\section{Breve análise espacial dos fluxos origem-destino do transporte rodoviário de carga}

Recibido: 9 de abril de 2018. Aceptado: 10 de septiembre de 2018.
Daniel Monteiro Huertas

Escola Paulista de Política, Economia e Negócios, Universidade Federal de São Paulo, campus Osasco, Brasil.

\section{Resumo}

A partir dos dados da Pesquisa Nacional de Tráfego 2011, elaborada pelo Ministério dos Transportes, este artigo propõe uma análise espacial dos fluxos do transporte rodoviário de carga, que correspondem a cerca de $65 \%$ do movimento total da matriz de transportes brasileira. A base de dados disponibilizada corresponde a uma matriz origem-destino com caminhões vazios e com carga, permitindo uma perspectiva analítica em três níveis escalares: nacional, macrorregional e mesorregional. Frete-retorno, relação entre pontos de produção e pontos de consumo, posição geográfica, nexos e arranjos territoriais e seletividade espacial são algumas variáveis que podem ser abordadas e discutidas, contribuindo para revelar o uso do território.

\section{Brief spatial analysis of origin-destination flows of road freight transport}

\section{Palavras-chave}

Transporte Rodoviário de Carga Matriz Origem-Destino Seletividade Espacial

\begin{abstract}
Based on data from the National Traffic Survey 2011, prepared by the Ministry of Transport, this paper proposes a spatial analysis of the flows of road freight transport, corresponding to about $65 \%$ of the total movement of the Brazilian transport matrix. The available database corresponds to an origin-destination matrix with empty and loaded trucks, allowing an analytical perspective in three scalar levels: national, macroregional and mesoregional. Freight return, relation between production points and points of consumption, geographic position, nexuses and territorial arrangements and spatial selectivity are some variables that can be approached and discussed, contributing to reveal the use of the territory.
\end{abstract}

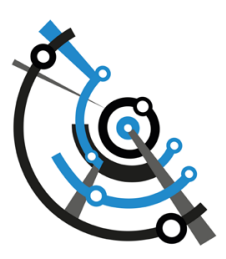

\section{Palabras clave}

Transporte de Carga por Carretera

Matriz Origen-Destino Selectividad Espacial

\section{Keywords}

Road Freight Transport Origin-Destiny Matrix Spatial Selectivity 


\section{Introdução}

Pesquisas amostrais para identificação dos pares origem-destino de viagens rodoviárias captam as suas motivações e seus atributos operacionais, espaciais e socioeconômicos, contribuindo para a formatação de uma matriz origem-destino que seja capaz de evidenciar a circulação em todo o seu escopo. Desse modo, o objetivo principal de uma pesquisa de tráfego é "conhecer, por intermédio de métodos sistemáticos de coleta de dados de tráfego e modelagem de transportes, o quantitativo de veículos que circulam por determinada via, assim como as origens e os destinos das viagens realizadas pelos diferentes tipos de veículos em determinada rede de transporte, em um período específico de tempo". ${ }^{1}$ A quantidade e a qualidade dessas pesquisas "demandam estudos específicos, modelos matemáticos, uso de sistemas computacionais dedicados e realização de eventos de campo com elevado grau de complexidade logística e operacional”."

A questão territorial é a que mais nos interessa, mas é preciso destacar que dados volumétricos e classificatórios (volume de tráfego, nível de serviço dos trechos rodoviários, tempo de viagem, tempo de coleta e/ou entrega das cargas, valor dos fretes praticados e relação entre tipo do veículo e natureza da carga), além da demonstração da alocação do tráfego em rede (distância, tempo e custo do transporte), também são importantes subsídios ao planejamento e ao conhecimento da realidade brasileira.

O objetivo principal deste artigo é procurar compreender, pelo menos em linhas gerais, a estrutura espacial dos fluxos origem-destino do transporte rodoviário de carga, sobretudo no que diz respeito ao frete-retorno e à questão regional. Advogamos a ideia de que o desequilíbrio verificado a partir das variáveis supracitadas reflete o próprio desenvolvimento desigual do país, que impacta diretamente a logística. Esta, tida como a versão atual da circulação corporativa e caracterizada por um conjunto de competências operacionais, materiais e normativas (Castillo, 2011), surge de forma arrebatadora e acarreta mudanças estruturais e conjunturais em toda a instância produtiva e no seu enlace com a circulação, aprofundando ainda mais a seletividade espacial e o uso do território.

Do ponto de vista metodológico, foi utilizada a Pesquisa Nacional de Tráfego (PNT) realizada em 2011 em conjunto pelos ministérios dos Transportes e da Defesa. Antes da análise direta da matriz origem-destino, entretanto, é necessário destacar que a promulgação da lei 11.442 , de 5 de janeiro de 2007, instituiu um novo quadro normativo e enquadrou o transporte rodoviário de carga (TRC) como aquele "realizado em vias públicas, no território nacional, por conta de terceiros e mediante remuneração", cuja atividade econômica "é de natureza comercial, exercida por pessoa física ou jurídica em regime de livre concorrência", segundo os artigos $1^{\circ}$ e $2^{\circ}$ da lei supracitada.

A norma, portanto, distingue o transporte rodoviário de carga da figura do carga própria (agente que não realiza o transporte com natureza comercial) e também procura discriminar e disciplinar os seus agentes (empresas de transporte rodoviário de carga/ETC e transportadores autônomos de carga/TAC, agregados e independentes) e atividades correlatas mediante coordenação e fiscalização da Agência Nacional de Transportes Terrestres (ANTT). Trata-se de um universo de 139.671 empresas transportadoras, 462.201 motoristas autônomos e 1.727 .061 veículos espalhados por todos os cantos do país, segundo dados da ANTT (28 mar. 2018).

Um aspecto importante da nova lei é o artigo $4^{\circ}$, que define a forma de prestação de serviço dos autônomos, como agregado ou independente, de acordo com o contrato a ser celebrado entre o TAC e a ETC e/ou o embarcador da carga. O TAC agregado é "aquele que coloca veículo de sua propriedade ou de sua posse, a ser dirigido por ele próprio ou por preposto
1. Extraído do seminário Pesquisa Nacional de Tráfego - 2011 (quadro 7), autoria de Marcelo Sampaio Cunha Filho, do Ministério dos Transportes. In: <http://servicos. dnit.gov.br/dadospnct/docs/ SeminariosPdf/pnt-2011-marcelosampaio-cunha-filho-o8.10.2014. pdf>. Acesso em: 20 mar. 2018.

2. Ibidem 
seu, a serviço do contratante, com exclusividade, mediante remuneração certa", enquanto o TAC independente "presta os serviços de transporte de carga de que trata esta Lei em caráter eventual e sem exclusividade, mediante frete ajustado a cada viagem”.

Mediante proposta que incorpora o escopo teórico de Milton Santos sobre os circuitos da economia urbana, no qual a diferença fundamental entre as atividades dos circuitos superior e inferior está ancorada nas diferenças de tecnologia e organização (Santos, 2008), no transporte rodoviário de carga essa questão se expressa nas relações de subordinação e complementaridade que ocorrem no que estamos chamando de "cadeia de subcontratações", gerando tensões e distensões entre os agentes que extrapolam o âmbito meramente intraurbano e compõem a dialética espacial entre os dois circuitos (Huertas, 2013), embora este fenômeno não seja o foco principal deste artigo.

Mas um dos pontos a serem analisados a partir dos fluxos da matriz origem-destino é a participação de cada circuito no total da circulação, levando-se em consideração que o circuito inferior, no transporte rodoviário de carga, é composto por caminhoneiros autônomos (agregados e independentes) e micro e pequenas empresas transportadoras de carga, cuja linha entre ambas muitas vezes é embaçada e tênue (Huertas, 2013). A trama fica ainda mais complexa ao inserir na análise a escala de atuação dos agentes, como será visto mais adiante.

\section{Breve histórico das pesquisas origem-destino no Brasil}

Embora os anuários estatísticos produzidos pelo Instituto Brasileiro de Geografia e Estatística (IBGE) já trouxessem dados mais gerais quanto às trocas inter-regionais, a contagem de tráfego no Brasil, intitulada Programa de Contagem Sistemática de Trânsito, foi iniciada pelo extinto Departamento Nacional de Estradas e Rodagem (DNER) em 1975, com a implantação de 14 postos de coleta nos estados do Rio de Janeiro, São Paulo e Minas Gerais. Com o nome de Plano Nacional de Contagem de Tráfego, a pesquisa ainda foi realizada em 1977, 1989, 1997 e 1998, e chegou a ter 285 postos em operação. Entretanto, em 2001 o programa foi paralisado em função de contingenciamentos orçamentários.

Somente em 2011, com o objetivo de gerar dados à revisão geral do Plano Nacional de Logística e Transportes (PNLT) - lançado pelo governo Lula em 2007 e que tinha utilizado com base de dados o Plano Diretor Nacional Estratégico de Pesagem, de 2005 -, o governo federal elaborou a Pesquisa Nacional de Tráfego (PNT). No ano seguinte, novos estudos foram desenvolvidos pelo Departamento Nacional de Infraestrutura Terrestre/DNIT (que substituiu o DNER após a sua extinção) por meio do Instituto de Pesquisas Rodoviárias (IPR), em parceria com a Universidade Federal de Santa Catarina (UFSC), resultando no Plano Nacional de Contagem de Tráfego (PNCT). Até o momento, entretanto, não foram disponibilizados os dados completos da pesquisa origem-destino do PNCT.

A PNT, base analítica deste artigo, foi realizada em 2011 pelos ministérios da Defesa e dos Transportes com várias parcerias e detectou, em três semanas distintas (21-27 de maio, 23-30 de setembro e 26 de novembro-2 de dezembro), 1,62 milhão de viagens (38,4\% realizadas por caminhão) para entrevista em 120 postos de coleta em rodovias federais ao longo do país (exceto no Distrito Federal, Amapá, Roraima e Amazonas), discriminados abaixo:

» Região Norte (6 postos): PA (BR-010), TO (BR-153/3), RO (BR-364) e AC (BR-364); 
» Região Nordeste (33 postos): BA (BRs 101, 110, 116/2, 242 e 407), SE (BR-101), AL (BRs 101/2 e 316), PE (BRs 101, 116, 122 e 232/2), PB (BRs 101 e 230), RN (BRs 101, 226, 304 e 405), CE (BRs 020 e 116/2), PI (BRs 135, 316/2 e 343) e MA (BRs $135 / 2,222$ e $316 / 2)$;

» Região Centro-Oeste (16 postos): GO (BRs 020, 050, 060, 070, 153 e 364), MS (BRs 060, 158, 163, 262 e 267/2) e MT (BRs 163/3 e 174);

》 Região Sudeste (36 postos): MG (BRs 040/2, 050/2, 116/2, 122, 135/2, 153/2, 262, 265, 267, 352, 354, 356, 365 e 381/3), RJ (BRs 040, 101, 116/2, 393 e 484), ES (BRs 101/2, 259 e 262) e SP (BRs 050, 116/2, 153 e 381);

» Região Sul (29 postos): PR (BRs 116/2, 277/4, 289, 369, 376 e 476), SC (BRs 101/4, $116,153,280,282 / 2$ e 470) e RS (BRs 116, 158/2, 290/3, 293, 392 e 472).

Os dados levantados forneceram subsídios para a elaboração de uma matriz origemdestino (Quadro 1 e Figuras 1, 2 e 3) do número absoluto de veículos com carga e vazios (e não por tonelagem) com alguns parâmetros que podem subsidiar analiticamente a relação entre caminhões carregados e fluxo total (caminhão com carga + caminhão vazio). ${ }^{3}$ Foram obtidas informações sobre volume de cargas, de passageiros e de viagens dos veículos, além da coleta de informações socioeconômicas dos usuários das rodovias.

Quadro 1. Matriz origem-destino dos fluxos rodoviários de carga. Fonte: Elaboração própria com base na Pesquisa Nacional de Tráfego 2011

\begin{tabular}{|c|c|c|c|c|c|c|c|c|c|}
\hline \multirow[t]{2}{*}{$\begin{array}{l}\text { UNIDADE DA } \\
\text { FEDERAÇÃO }\end{array}$} & \multicolumn{3}{|c|}{$\begin{array}{l}\text { MOVIMENTO TOTAL } \\
\text { (com carga + vazio) }\end{array}$} & \multicolumn{3}{|c|}{ COM CARGA } & \multicolumn{3}{|c|}{ VAZIO } \\
\hline & $\begin{array}{l}\text { fluxo } \\
\text { total }\end{array}$ & origem & destino & $\begin{array}{l}\text { fluxo } \\
\text { total }\end{array}$ & origem & destino & fluxo total & origem & destino \\
\hline \multicolumn{10}{|l|}{ REGIÃO NORTE } \\
\hline $\mathrm{AC}$ & 2.510 & 1.184 & 1.326 & 1.416 & 416 & 1.000 & 1.094 & 768 & 326 \\
\hline AM & 602 & 276 & 326 & 451 & 189 & 262 & 151 & 87 & 64 \\
\hline $\mathrm{AP}$ & 520 & 224 & 296 & 329 & 113 & 216 & 191 & 111 & 80 \\
\hline PA & 15.263 & 7.245 & 8.018 & 11.790 & 4.892 & 6.898 & 3.473 & 2.353 & 1.120 \\
\hline RO & 7.754 & 3.506 & 4.248 & 5.006 & 2.155 & 2.851 & 2.748 & 1.351 & 1.397 \\
\hline RR & 137 & 67 & 70 & 101 & 53 & 48 & 36 & 14 & 22 \\
\hline TO & 5.813 & 2.663 & 3.150 & 3.407 & 1.415 & 1.992 & 2.406 & 1.248 & 1.158 \\
\hline Total & 32.599 & 15.165 & 17.434 & 22.500 & 9.233 & 13.267 & 10.099 & 5.932 & 4.167 \\
\hline \multicolumn{10}{|c|}{ REGIÃO NORDESTE } \\
\hline $\mathrm{AL}$ & 5.255 & 2.600 & 2.655 & 3.268 & 1.443 & 1.825 & 1.987 & 1.157 & 830 \\
\hline BA & 37.620 & 18.676 & 18.944 & 24.402 & 12.186 & 12.216 & 13.218 & 6.490 & 6.728 \\
\hline CE & 16.256 & 7.642 & 8.614 & 11.160 & 4.773 & 6.387 & 5.096 & 2.869 & 2.227 \\
\hline MA & 12.606 & 5.841 & 6.765 & 8.289 & 3.189 & 5.100 & 4.317 & 2.652 & 1.665 \\
\hline PB & 8.964 & 4.567 & 4.397 & 5.143 & 2.435 & 2.708 & 3.821 & 2.132 & 1.689 \\
\hline $\mathrm{PE}$ & 21.083 & 10.363 & 10.720 & 13.137 & 6.622 & 6.515 & 7.946 & 3.741 & 4.205 \\
\hline $\mathrm{PI}$ & 6.373 & 2.916 & 3.457 & 4.017 & 1.637 & 2.380 & 2.356 & 1.279 & 1.077 \\
\hline $\mathrm{RN}$ & 9.140 & 4.749 & 4.391 & 5.706 & 2.787 & 2.919 & 3.434 & 1.962 & 1.472 \\
\hline SE & 5.080 & 2.589 & 2.491 & 3.342 & 1.789 & 1.553 & 1.738 & 800 & 938 \\
\hline Total & 122.377 & 59.943 & 62.434 & 78.464 & 36.861 & 41.603 & 43.913 & 23.082 & 20.831 \\
\hline DF & 6.113 & 2.679 & 3.434 & 4.150 & 1.473 & 2.677 & 1.963 & 1.206 & 757 \\
\hline $\mathrm{GO}$ & 24.690 & 12.751 & 11.939 & 16.445 & 8.918 & 7.527 & 8.245 & 3.833 & 4.412 \\
\hline MS & 18.667 & 9.229 & 9.438 & 10.586 & 5.275 & 5.311 & 8.151 & 4.024 & 4.127 \\
\hline MT & 41.187 & 20.851 & 20.336 & 27.417 & 14.700 & 12.717 & 13.770 & 6.151 & 7.619 \\
\hline Total & 90.657 & 45.510 & 45.147 & 58.598 & 30.366 & 28.232 & 32.129 & 15.214 & 16.915 \\
\hline
\end{tabular}

3. Apesar de ainda contar com sítio ativo (vide <http://www.pnt2011. com.br/index.cfm>, acesso em: 20 mar. 2018), os dados primários da pesquisa não estão mais disponíveis. $\mathrm{O}$ autor compilou os números das três variáveis (caminhão cheio, caminhão vazio e movimento total) de todas as 27 Unidades da Federação em 07 ago. 2012 e gerou uma planilha para cada uma delas, que serviram de cada uma delas, que serviram de
base para a análise em questão. 


\begin{tabular}{|l|c|c|c|c|c|c|c|c|c|}
\hline REGIÃO SUDESTE \\
\hline ES & 12.718 & 6.332 & 6.386 & 7.949 & 4.022 & 3.927 & 4.769 & 2.310 & 2.459 \\
\hline MG & 63.511 & 31.648 & 31.863 & 40.922 & 20.393 & 20.529 & 22.589 & 11.255 & 11.334 \\
\hline RJ & 18.538 & 8.828 & 9.710 & 12.722 & 5.712 & 7.010 & 5.816 & 3.116 & 2.700 \\
\hline SP & 79.577 & 40.555 & 39.022 & 55.017 & 29.429 & 25.588 & 24.560 & 11.126 & 13.434 \\
\hline Total & 174.344 & 87.363 & 86.981 & 116.610 & 59.556 & 57.054 & 57.734 & 27.807 & 29.927 \\
\hline REGIÃO SUL & 59.084 & 30.714 & 28.370 & 38.860 & 21.021 & 17.839 & 20.224 & 9.693 & 10.531 \\
\hline PR & 43.624 & 22.350 & 21.274 & 27.726 & 14.236 & 13.490 & 15.898 & 8.114 & 7.784 \\
\hline RS & 40.581 & 20.553 & 20.028 & 26.180 & 13.196 & 12.984 & 14.401 & 7.357 & 7.044 \\
\hline SC & 143.289 & 73.617 & 69.672 & 92.766 & 48.453 & 44.313 & 50.523 & 25.164 & 25.359 \\
\hline Total & 563.266 & 281.598 & 281.668 & 368.938 & 184.469 & 184.469 & 194.398 & 97.199 & 97.199 \\
\hline BRASIL & \multicolumn{7}{|c|}{}
\end{tabular}

Do ponto de vista tecnológico, para a coleta de dados foi elaborado um aplicativo para o iPad com um fluxo de perguntas, de modo a agilizar o processo da entrevista. Outra vantagem é que os dados foram armazenados no $i \mathrm{Pad}$ e depois transferidos para um notebook, que os enviou para o banco de dados do servidor, facilitando a sua sistematização e contabilização. Em todos os postos distribuídos pelas rodovias do país, as entrevistas foram realizadas pelos militares do Exército.

Dentre os principais objetivos da PNT 2011 estão o conhecimento do tráfego ao longo dos principais corredores rodoviários, fator determinante para a identificação de alocação dos investimentos, e o fornecimento de dados para alimentação de modelos de análise que serão utilizados em ações relacionadas ao planejamento de transportes. Considerando a abrangência territorial e a distribuição das rodovias pelas macrorregiões brasileiras, a realização dessa pesquisa "demandou estudos específicos, uso de equipamentos de última geração e treinamento de campo com elevado grau de complexidade logística e operacional, de forma a garantir o levantamento de uma quantidade suficiente de informações com qualidade e consistência".

4. In: <http://www.pnt2011.com. br/pesquisa principal.cfm>. Acesso em: 20 mar. 2018.

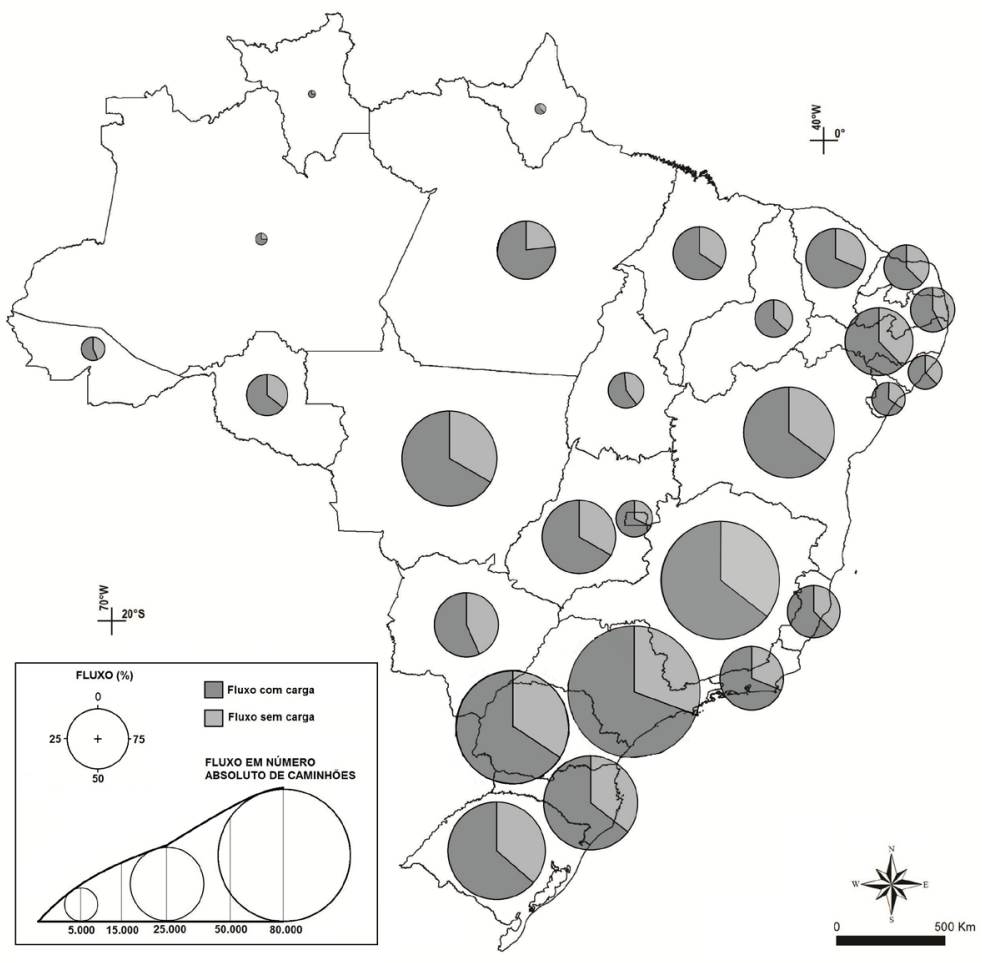




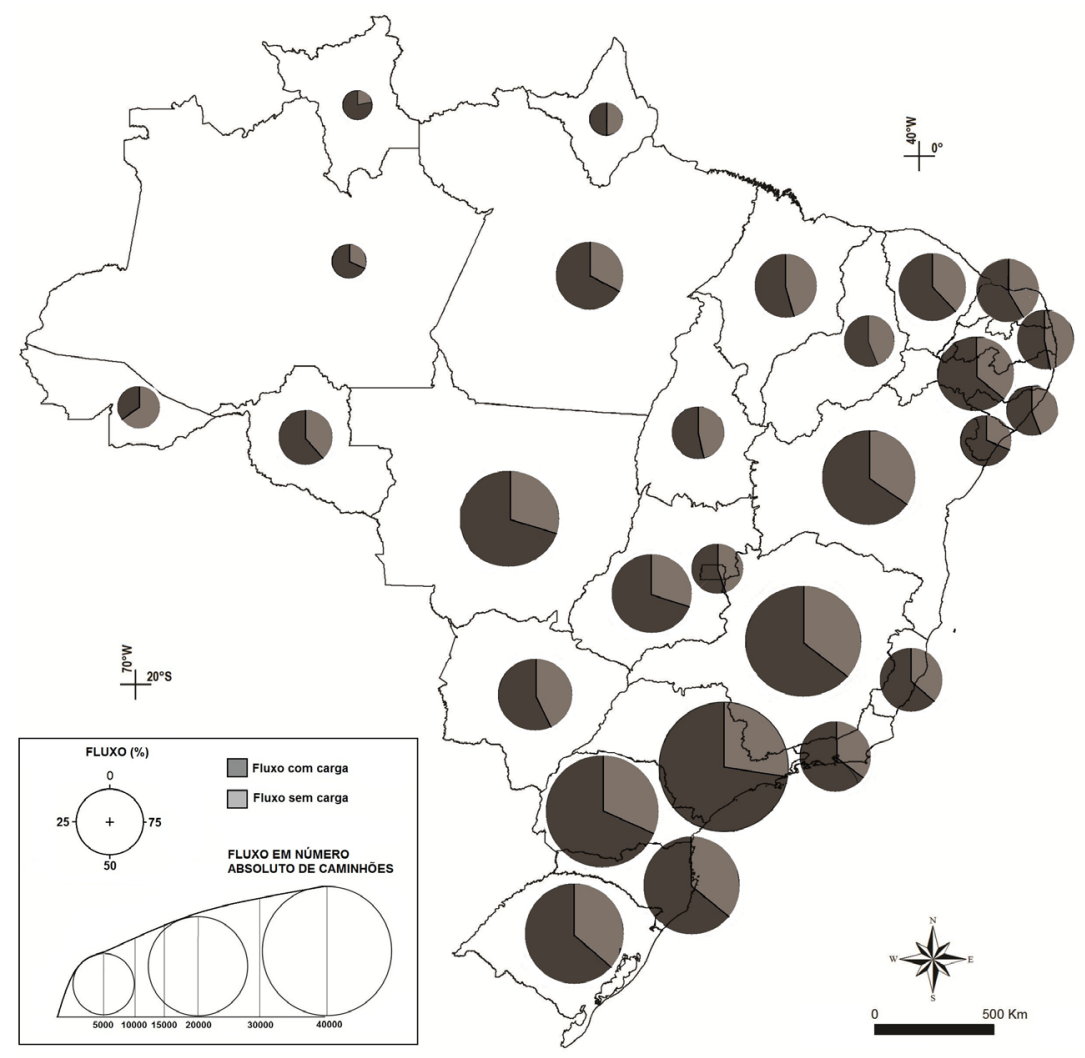

Figura 2. Fluxos de origem. Fonte: Elaboração própria com base na Pesquisa Nacional de Tráfego 2011. Elaboração cartográfica: Giuliano T. Novais.

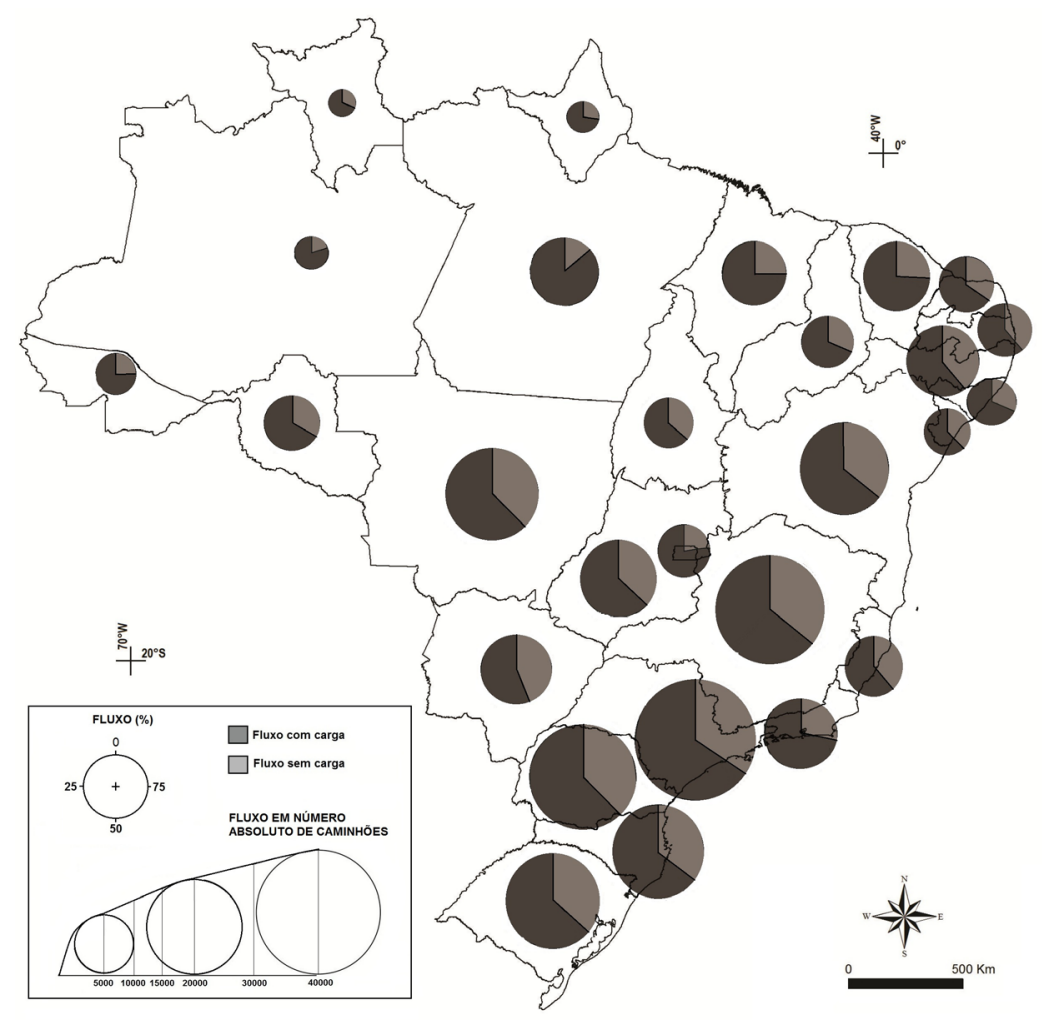

Figura 3. Fluxos de destino. Fonte: Elaboração própria com base na Pesquisa Nacional de Tráfego 2011. Elaboração cartográfica: Giuliano T. Novais. 
Apenas a título de registro, na edição 192 (setembro de 2011) da revista Transporte Atual a Confederação Nacional dos Transportes (CNT) informou, por meio de uma nota, a descontinuidade do Índice de Desempenho Econômico do Transporte (Idet), que era produzido mensalmente em parceria com a Fundação Instituto de Pesquisas Econômicas (Fipe). O levantamento considerava todos os modais e o transporte de passageiros e de carga, cujo total movimentado (em toneladas), sistematizado em uma matriz origem-destino, era composto por seis grupos:

» Carga agrícola: 10 produtos que representam $90 \%$ do total produzido, subdivididos em exportação (UF produtora-porto) e consumo interno;

» Carga pecuária: rebanho bovino, suíno e aves;

» Hortifrutigranjeiros;

» Extrativismo vegetal: madeira em tora e lenha;

» Combustíveis: refinarias e postos de vendas;

» Carga industrial: empresas com frota própria e ETCs.

A seguir apresentaremos uma análise dos dados centralizada na dinâmica regional e no frete-retorno.

\section{Escalas de atuação do transporte rodoviário de carga}

Quanto às escalas de atuação do transporte rodoviário de carga, o caso brasileiro é bastante peculiar por conta da extensão continental de seu território e de suas desigualdades regionais quanto à renda, população e configuração da malha rodoviária. Desse modo, entendemos que as escalas de atuação do TRC podem ser compreendidas a partir da relação entre níveis escalares básicos (nacional, regional e local), rede urbana e posição geográfica das 27 Unidades da Federação e das cinco regiões político-administrativas do país. A partir deste pressuposto distinguimos dois tipos de movimento com funções diferenciadas (Huertas, 2013):

Os fluxos T1 (transferência primária) ligam dois pontos (A-B) e territorialmente conectam os mercados com maior demanda, tanto por bens de consumo quanto por insumos, fator que gera economias de escala (Figura 4). Como via de regra, com poucas exceções, tais pontos estão situados estrategicamente na rede rodoviária nacional, com acessos otimizados aos principais eixos viários e mercados consumidores do país. Os fixos responsáveis pelas transferências, transbordos e consolidação de carga, características operacionais inerentes aos fluxos T1, exigem gestão e operação com maior grau de complexidade, pois precisam estar preparados para a realização de atividades que demandam precisão, rapidez e coordenação. São subdivididos em:

» T1/A - escala nacional (ligação interregional). Ex: Sul $\leftrightarrow$ Sudeste; Norte↔Sul;

» T1/B - escala macrorregional (ligação interregional + interestadual contígua e/ou ligação intrarregional + interestadual). Ex: $\mathrm{PA} \leftrightarrow \mathrm{MA}$; $\mathrm{SP} \leftrightarrow \mathrm{PR}$ e/ou $\mathrm{BA} \leftrightarrow \mathrm{CE}$;

» T1/C - escala mesorregional (ligação intraestadual entre pólos regionais). Ex: Campina Grande $\leftrightarrow$ Patos (PB); Santa Maria↔Pelotas (RS); Cuiabá $\leftrightarrow$ Sinop (MT). 


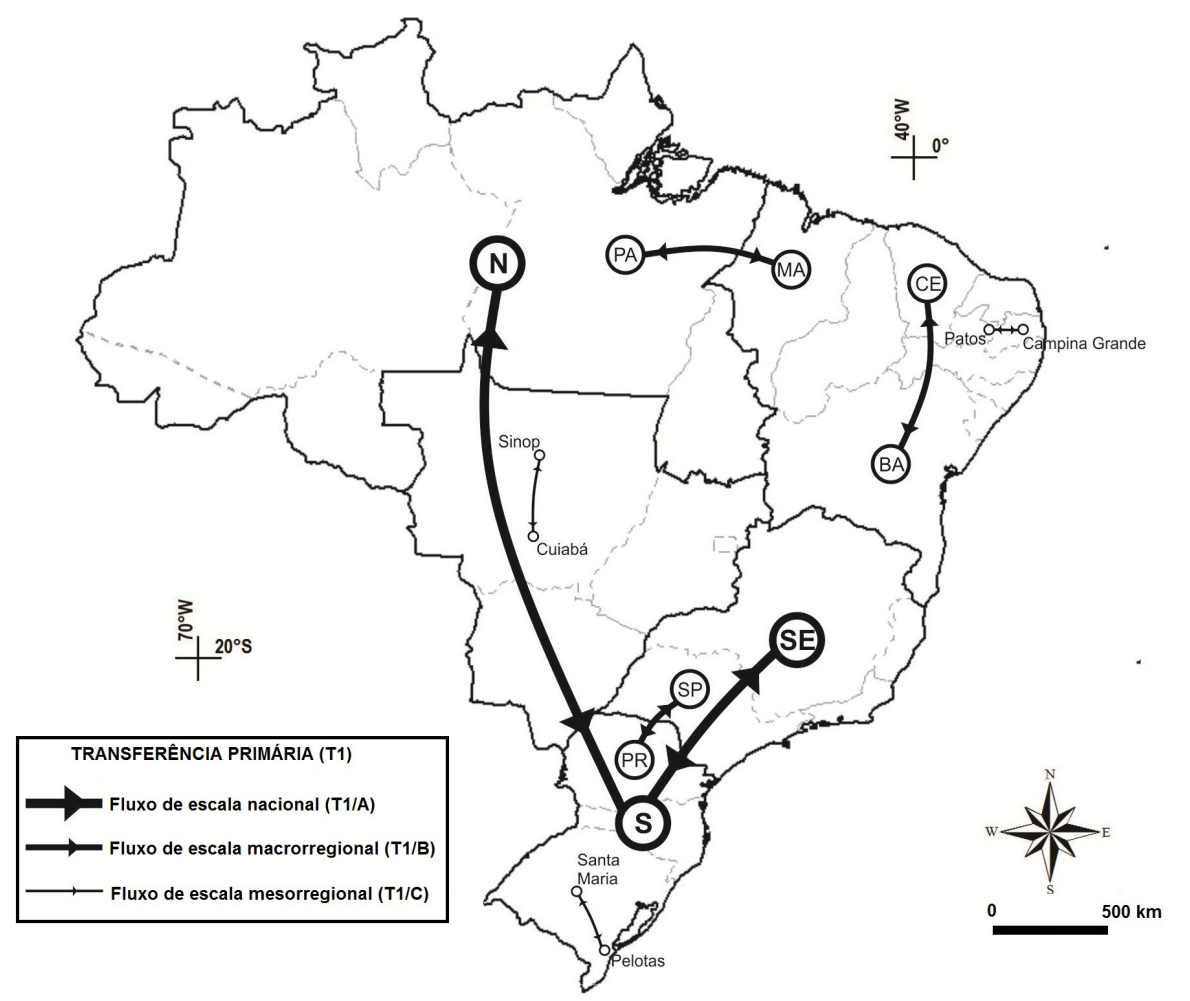

Figura 4. Fluxos de transferência primária (T1). Fonte: Elaboração própria. Elaboração cartográfica: Giuliano T. Novais.

Os fluxos T2 (transferência secundária) são típicos de carga fracionada e similares a linhas regulares de ônibus, com rota fixa e cumprimento de horário (Figuras 5 e 6). Por conta desta característica conectam vários pontos em uma mesma operação e ficam submetidos a uma variável do período atual com forte conteúdo informacional, a roteirização, que nada mais é do que a programação de rotas em softwares específicos (geralmente procedimentos matemáticos de programação linear). São subdivididos em:

» T2/D - escala microrregional (ligação intraestadual a partir de um pólo regional). Ex: Sinop $\leftrightarrow$ Santa Carmen $\leftrightarrow$ União do Sul $\leftrightarrow$ Marcelândia $\leftrightarrow$ Cláudia (MT);

" T2/E - escala intraurbana metropolitana (ligação entre cidades de região metropolitana ou entre zonas/bairros das metrópoles). Ex: Belo Horizonte $\leftrightarrow$ Ribeirão das Neves; Belém↔Benfica; Vila Maria $\leftrightarrow$ Santo Amaro (São Paulo); Ramos $\leftrightarrow$ Copacabana (Rio de Janeiro); Porto Seco↔Azenha (Porto Alegre);

» T2/F - escala intraurbana intermediária (ligação entre zonas/bairros de capitais estaduais e/ou cidades intermediárias fora do âmbito metropolitano). Ex: centro↔Vila Carvalho (Ribeirão Preto); Santa Mônica↔Fundinho (Uberlândia). 


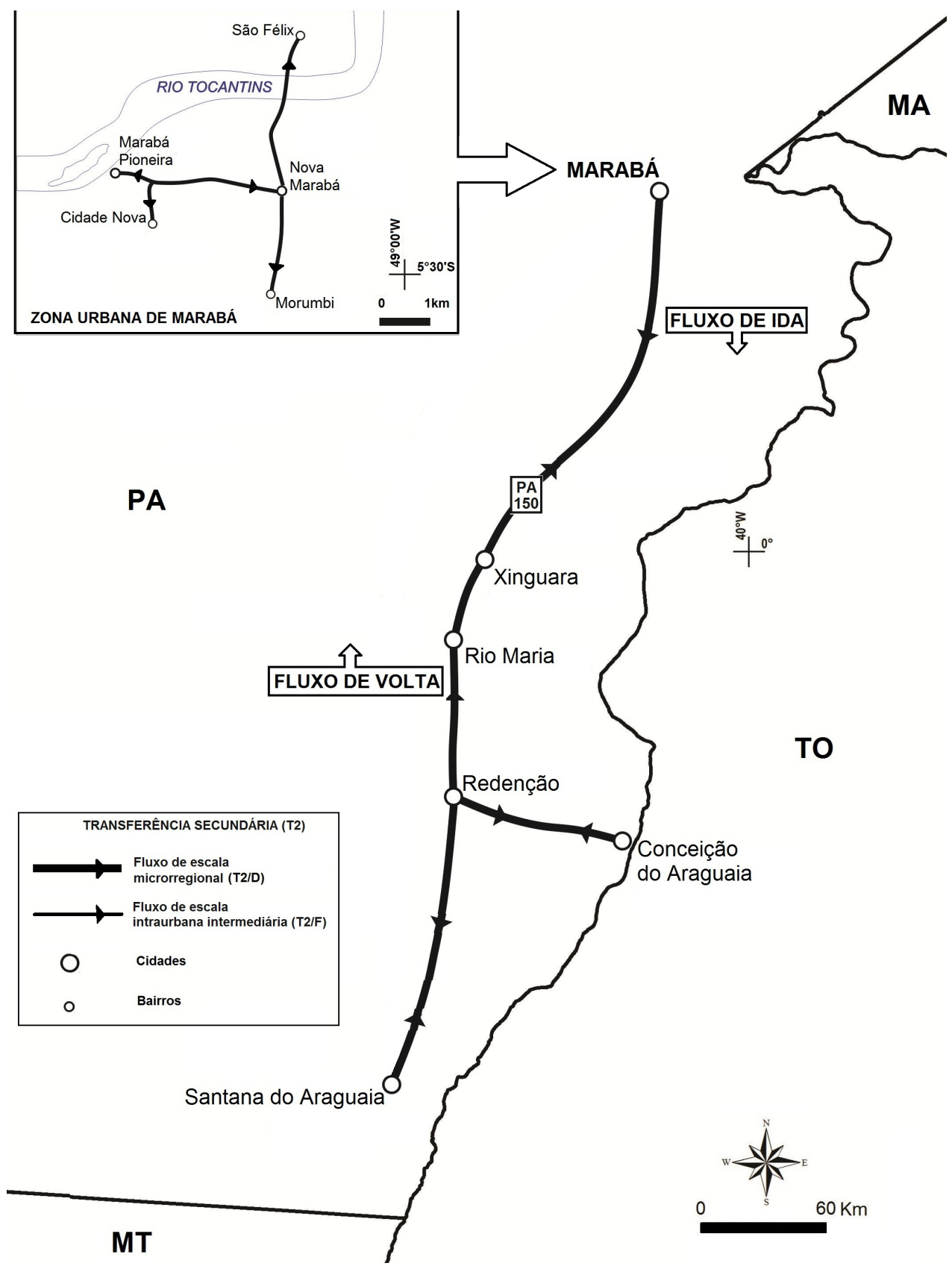

Figura 5. Fluxos de transferência secundária T2/D e T2/F. Fonte: Elaboração própria. Elaboração cartográfica: Giuliano T. Novais. 


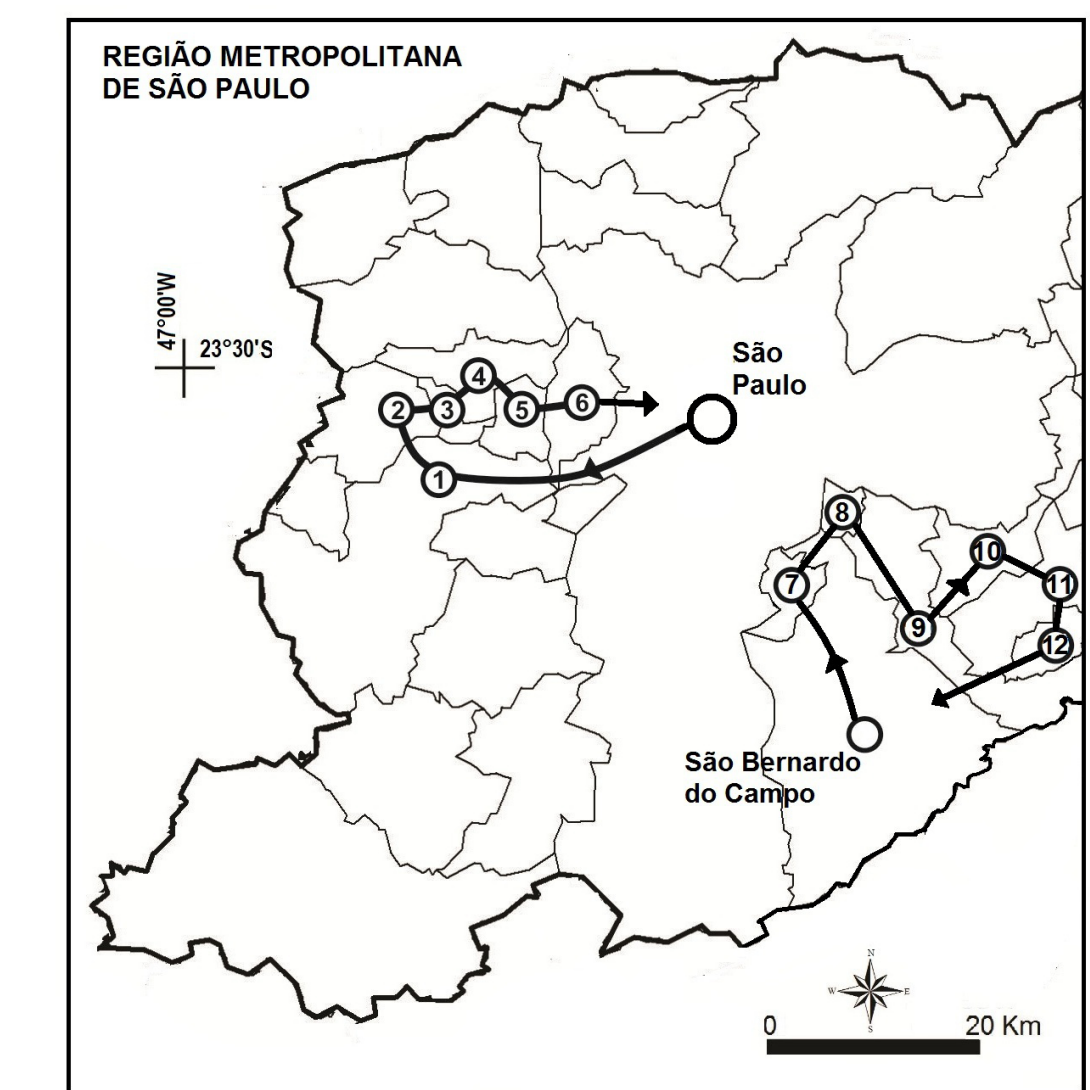

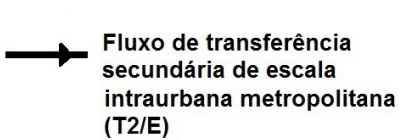

(T2/E)

\section{Exemplos hipotéticos de fluxos}

Rota 1: São Paulo - Cotia (1) - Itapevi (2) - Jandira (3) - Barueri (4) Carapicuiba (5) - Osasco (6)

Rota 2: São Bernardo do Campo - Diadema (7) - São Caetano do Sul (8) - Santo André (9) - Mauá (10) - Ribeirão Pires (11) - Rio Grande da Serra (12)

Figura 6. Fluxos de transferência secundária T2/E. Fonte: Elaboração própria. Elaboração cartográfica: Giuliano T. Novais.

Como será visto em seguida levaremos em consideração todos os fluxos T1 e os fluxos $\mathrm{T} 2 / \mathrm{D}$, já que T2/E e T2/F representam escalas que não se enquadram na proposta analítica deste artigo.

\section{Um foco analítico sobre a dinâmica regional}

Os dados da PNT 2011, sob o ângulo da dinâmica regional do transporte rodoviário de carga, revelam três fenômenos bastante proeminentes - e que, em linhas gerais, se repetem na modalidade caminhão vazio, caminhão cheio e movimento total (cheio + vazio) em ambos os movimentos (origem e destino):

A relevância do movimento intraestadual (destacado em azul nos quadros 2 e 3 ), que coincide com os fluxos T1/C e T2/D;

O papel central do estado de São Paulo no âmbito nacional (destacado em verde nos quadros 2 e 3 ); 
Como variáveis de destaque a circulação intrarregional (destacado em vermelho nos quadros 2 e 3) e inter-regional contígua (entre Unidades da Federação limítrofes de macrorregiões distintas, como, por exemplo, Minas Gerais-Goiás, Pará-Maranhão e São Paulo-Paraná), que coincidem com os fluxos T1/B. Neste caso, um fluxo é considerado bidirecional quando, em um mesmo movimento (total, com carga ou vazio), seja na origem e/ou no destino, aparece de forma simultânea entre os principais de duas UFs (como $\mathrm{SE} \rightarrow \mathrm{AL}$ e $\mathrm{AL} \rightarrow \mathrm{SE}$, tornando-se $\mathrm{SE} \leftrightarrow \rightarrow \mathrm{AL}$ ).

Para facilitar a compreensão desses fenômenos, elaboramos uma análise separada para cada macrorregião do país a partir de dados destacados, para cada unidade da Federação, do número total de caminhões registrados e das três principais origens (Quadro 2) e dos três principais destinos (Quadro 3) da carga. 


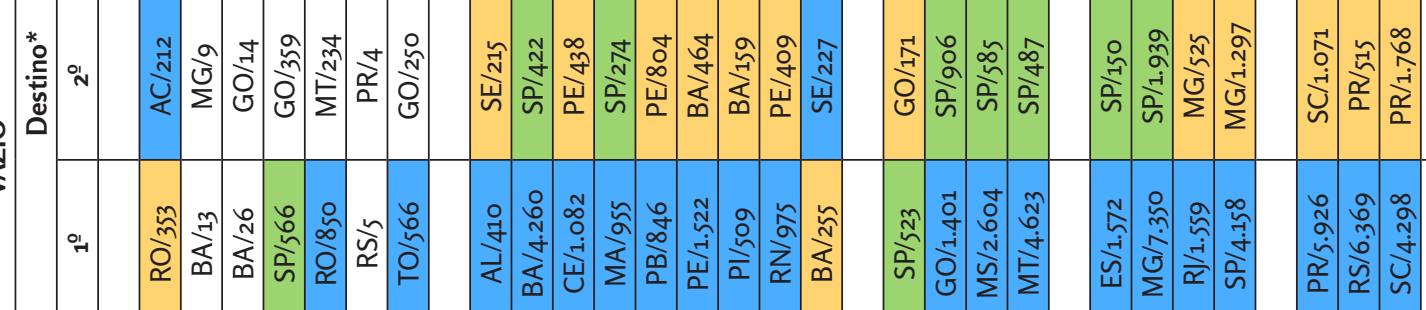

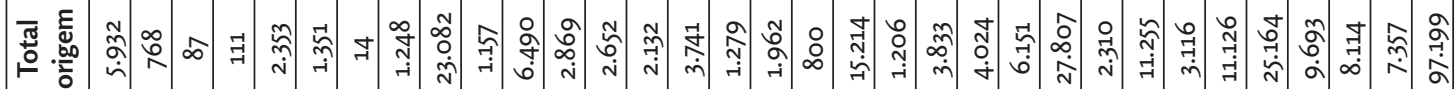

\section{Љ)}

\section{वิ)

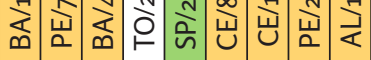

\section{ำ

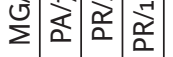

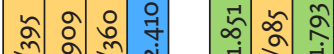

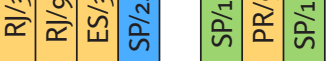

ปัّ

ำ

oิ

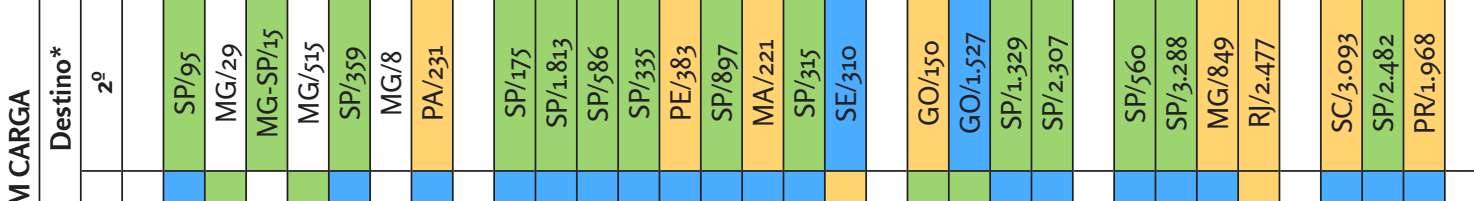

赵.

ช ขั

ठำ

ㅇำ

ปิ

0 范

胥

ㄴํำ 응

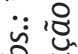

กิ ช

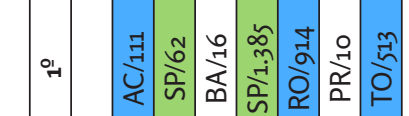

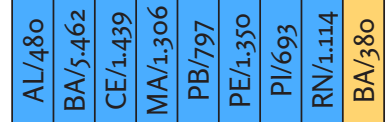

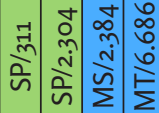

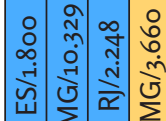

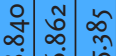

$\frac{\sqrt{2}}{\frac{2}{2}} \stackrel{\frac{1}{2}}{\infty}$

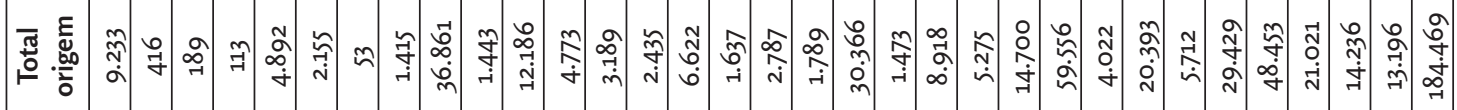

ஸे $\frac{0}{2}$

站茪

$\frac{\mathrm{\sigma}}{\mathrm{\sigma}}$ 나

है.

$\cong$

๖ั

हิ

ำ

$8 \frac{1}{4}$

กั

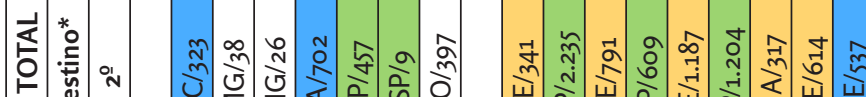

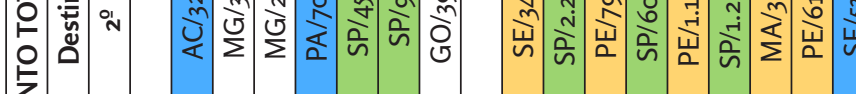

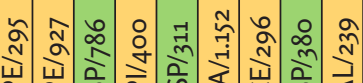

๙ิ)

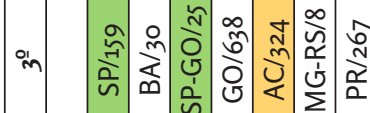

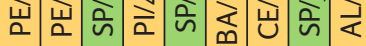

$\sum \sum \frac{5}{\Sigma} \sum \frac{\sqrt{2}}{2}$

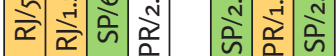

$\frac{\pi}{3} \frac{0}{3}$

i

옹 ำ

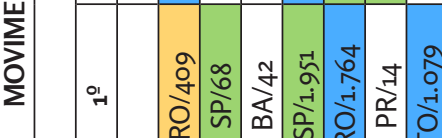

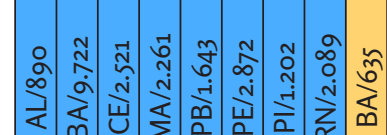

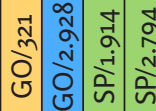

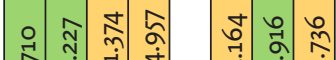

जे जिए

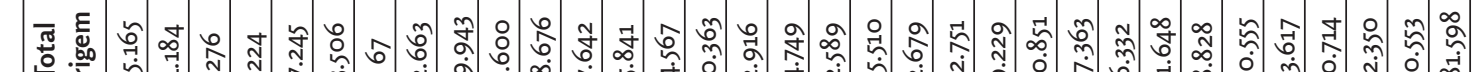

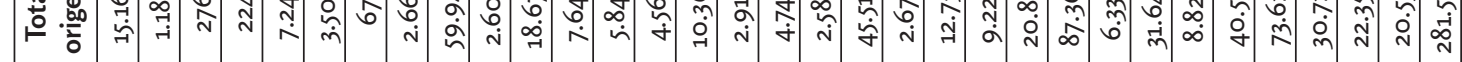




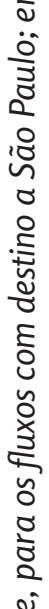

ิㅗํ 군

ㄷํㅇㅇㅡ

苍客

궁 은

ปัป రิ

.

กิธ

ธิธ

రั ర

ㅇำ

ิㅡำ

ปัँ

ฟิ่

ह

湈

$\ddot{\circ}$

ที่

气ั

है

व. .

웡

ปั

온.

ปั

온

ป

혼

ก่

음 $\frac{2}{0}$

\begin{tabular}{|c|c|c|c|c|c|c|c|c|c|c|c|c|c|c|c|c|c|c|c|c|c|c|c|c|c|c|c|c|}
\hline \multirow{3}{*}{ 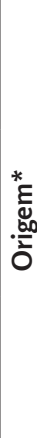 } & in & $\frac{a}{\hat{n}}$ & $\frac{\hat{n}}{\hat{n}}$ & $\stackrel{a}{\gtrless}$ & 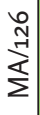 & 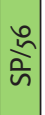 & 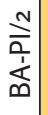 & $\begin{array}{l}0 \\
\stackrel{2}{a} \\
\frac{1}{2}\end{array}$ & $\begin{array}{l}\vec{b} \\
\stackrel{-1}{\alpha}\end{array}$ & $\frac{\mathfrak{m}}{\stackrel{N}{J}}$ & 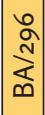 & 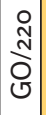 & $\frac{n}{\varkappa_{\varkappa}}$ & $\begin{array}{l}\stackrel{a}{0} \\
\stackrel{m}{a}\end{array}$ & 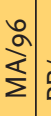 & 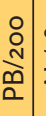 & 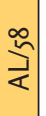 & $\begin{array}{l}\curvearrowright \\
\text { ○े } \\
\text { ర్ }\end{array}$ & $\underset{\substack{a \\
\Sigma}}{\stackrel{a}{a}}$ & $\begin{array}{l}\vec{N} \\
\stackrel{N}{\alpha} \\
\stackrel{\alpha}{\Delta}\end{array}$ & 啇 & $\frac{\hat{\pi}}{\frac{\pi}{n}}$ & $\frac{\nwarrow}{\grave{\Upsilon}}$ & 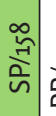 & 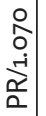 & $\left|\begin{array}{c}\tilde{\hat{o}} \\
\hat{i} \\
\hat{i} \\
\tilde{n}\end{array}\right|$ & $\begin{array}{l}\hat{a} \\
\frac{\hat{a}}{\alpha} \\
\end{array}$ & $\frac{\hat{N}}{\frac{\hat{0}}{\hat{n}}}$ \\
\hline & 이 & 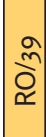 & $\stackrel{\circ}{\stackrel{0}{2}}$ & $\frac{\vec{z}}{\stackrel{a}{\alpha}}$ & $\begin{array}{l}\infty \\
0 \\
\text { N} \\
\\
\text { ñ }\end{array}$ & 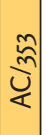 & $\begin{array}{l}\tilde{y} \\
\grave{n} \\
\check{n}\end{array}$ & 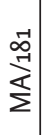 & $\begin{array}{l}\tilde{N} \\
\tilde{\omega}\end{array}$ & $\begin{array}{c}\tilde{N} \\
\frac{y}{n} \\
\bar{n}\end{array}$ & 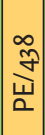 & $\begin{array}{c}\frac{d}{N} \\
\frac{\mathbf{n}}{n}\end{array}$ & 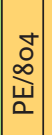 & 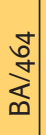 & 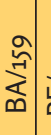 & 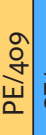 & $\begin{array}{c}\hat{y} \\
\text { Wు }\end{array}$ & $\begin{array}{l}\infty \\
\frac{a}{n} \\
\tilde{n}\end{array}$ & $\begin{array}{l}\infty \\
0 \\
0 \\
\vdots \\
\tilde{n}\end{array} \mid$ & $\begin{array}{l}\frac{0}{0} \\
\frac{0}{n}\end{array}$ & 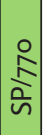 & $\frac{\tilde{\rho}}{\overline{\tilde{\alpha}}}$ & 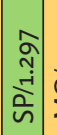 & 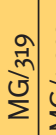 & 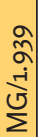 & 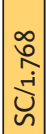 & $\begin{array}{c}\frac{2}{m} \\
\stackrel{n}{n}\end{array}$ & $\frac{\alpha}{2}$ \\
\hline & $\stackrel{\circ}{{ }_{1}}$ & $\mid \begin{array}{l}n \\
\text { N } \\
\text { Uे }\end{array}$ & $\frac{\vec{z}}{\frac{7}{\alpha}}$ & $\begin{array}{l}\stackrel{0}{N} \\
\stackrel{\infty}{\infty}\end{array}$ & $\begin{array}{c}\mathfrak{N} \\
\stackrel{0}{n} \\
\stackrel{n}{a}\end{array}$ & 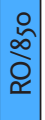 & $\frac{0}{2}$ & 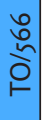 & $\begin{array}{l}\frac{0}{y} \\
\frac{7}{2}\end{array}$ & 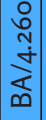 & 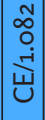 & $\frac{\tilde{\alpha}}{\vdots}$ & $\left|\begin{array}{l}0 \\
\infty \\
\infty \\
\check{\alpha}\end{array}\right|$ & 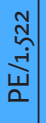 & 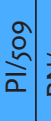 & 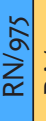 & 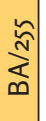 & 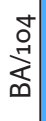 & 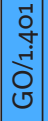 & $\begin{array}{l}\stackrel{+}{0} \\
\stackrel{1}{\mathbf{s}} \\
\stackrel{n}{\Sigma}\end{array}$ & $\begin{array}{c}\text { } \\
\tilde{b} \\
\dot{+} \\
\stackrel{\Xi}{\Sigma}\end{array}$ & 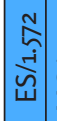 & 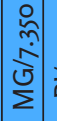 & 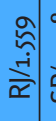 & $\begin{array}{c}\stackrel{\infty}{\mathfrak{d}} \\
\stackrel{+}{+} \\
\text { जे }\end{array}$ & $\left|\begin{array}{c}0 \\
\tilde{N} \\
\dot{\sim} \\
\stackrel{\alpha}{\alpha}\end{array}\right|$ & 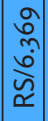 & 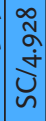 \\
\hline
\end{tabular}

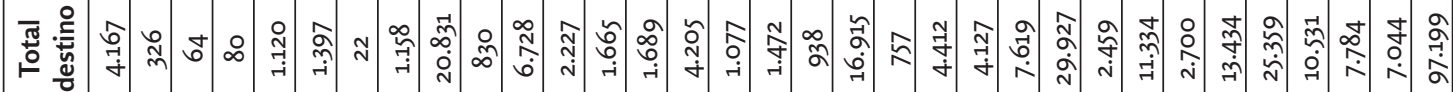

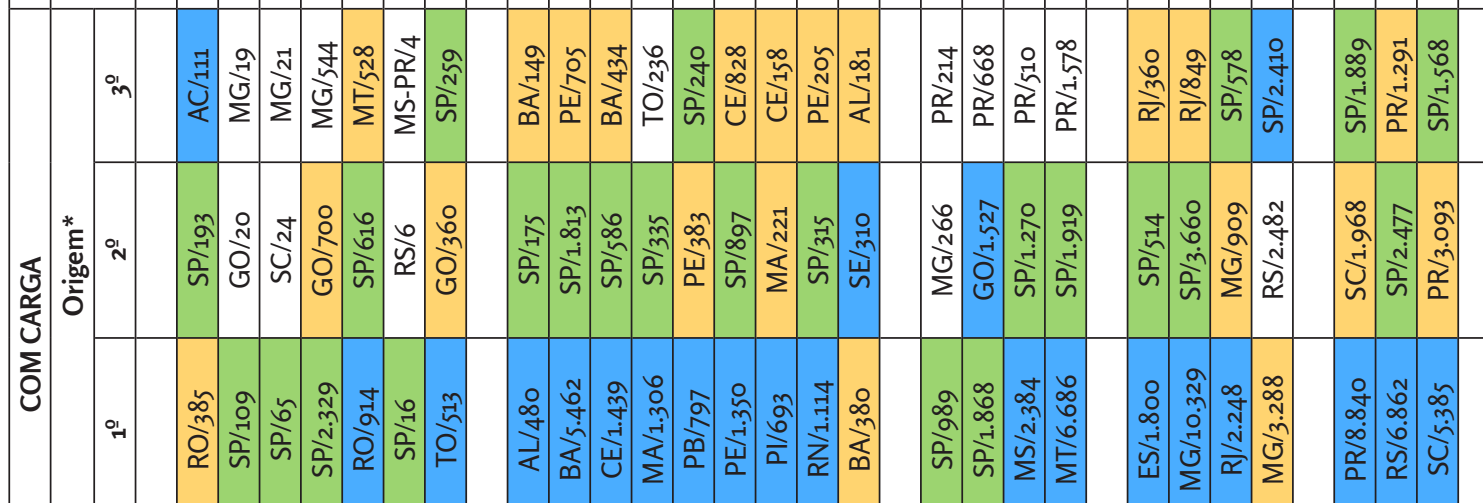

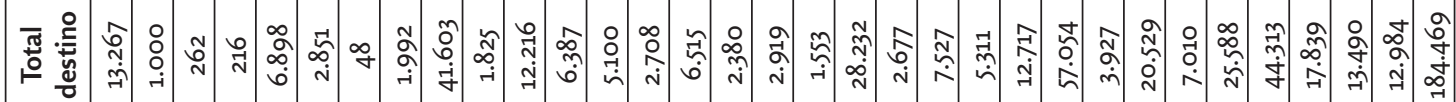

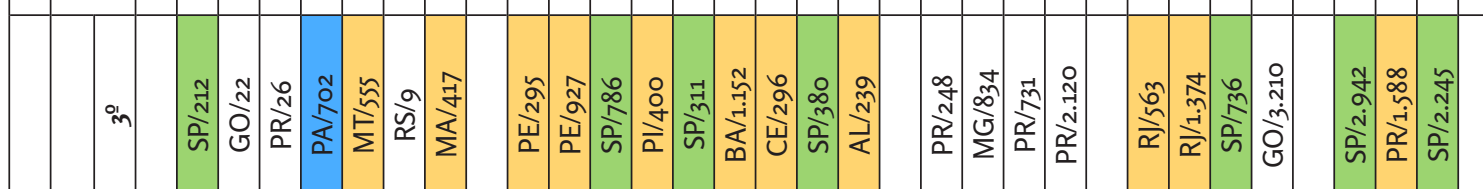

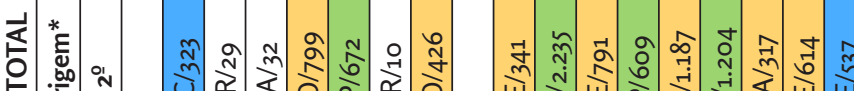

일

ì

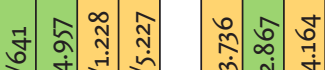

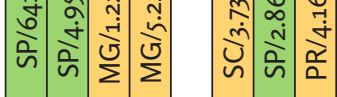

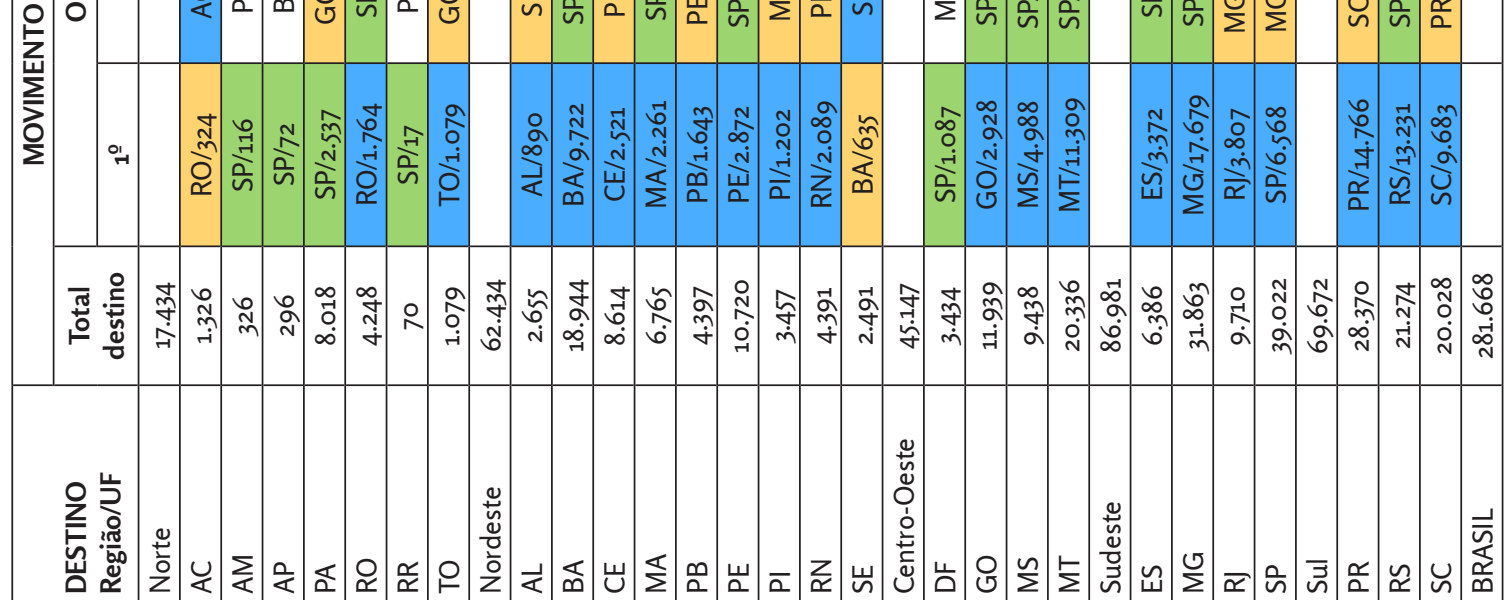




\section{Região Norte}

De imediato cabe registrar que Amazonas, Roraima e Amapá não aparecem na dinâmica intraestadual, seja como origem ou destino, por um motivo simples: a ausência de postos de coleta da PNT nesses Estados. No caso do Amazonas, a dependência excessiva do transporte hidroviário para distribuição em boa parte de seu território (de seus 62 municípios, apenas 15 são acessados por via rodoviária) complica ainda mais a captação dessa dinâmica.

Fluxos de origem: a circulação intraestadual representa $25,5 \%$ do movimento total, $20,9 \%$ do movimento com carga e $32,5 \%$ do movimento vazio. São Paulo como destino aparece com $18,9 \%$ do movimento total, $22,02 \%$ do movimento com carga e $14,2 \%$ do movimento vazio. A circulação intrarregional representa $11,3 \%$ do movimento total, $8,4 \%$ do movimento com carga e $10,7 \%$ do movimento vazio.

Fluxos de destino: a circulação intraestadual representa 22,1\% do movimento total, $14,6 \%$ do movimento com carga e $46,3 \%$ do movimento vazio. São Paulo como origem aparece com 22,5\% do movimento total, 27,03\% do movimento com carga e 8,06\% do movimento vazio. A circulação intrarregional representa $7,9 \%$ do movimento total, $5,8 \%$ do movimento com carga e $15,2 \%$ do movimento vazio.

Circulação intrarregional + inter-regional contígua (fluxos incluídos entre os três principais de origem e destino em todos os movimentos): bidirecionais [AC↔RO/3] e unidirecionais $[\mathrm{RO} \rightarrow \mathrm{AC} / 2$ e $\mathrm{AC} \rightarrow \mathrm{RO} / 1],[\mathrm{TO} \rightarrow \mathrm{PA} / 2 \mathrm{e} \mathrm{PA} \rightarrow \mathrm{TO} / 1]$, [TO $\rightarrow \mathrm{GO} / 2 \mathrm{e} \mathrm{GO} \rightarrow \mathrm{TO} / 2$ ], $[\mathrm{PA} \rightarrow \mathrm{GO} / 2$ e $\mathrm{GO} \rightarrow \mathrm{PA} / 2],[\mathrm{MT} \rightarrow \mathrm{RO} / 2$ e $\mathrm{RO} \rightarrow \mathrm{MT} / 1],[\mathrm{MA} \rightarrow \mathrm{TO} / 2$ e $\mathrm{TO} \rightarrow \mathrm{MA} / 1]$ e $[\mathrm{MA} \rightarrow \mathrm{PA} / 1]$. A ocorrência de fluxos intensos entre Pará, Tocantins e Goiás provavelmente é herança da ligação histórica entre estes Estados - e cabe lembrar que o Tocantins, criado em 1988, era o antigo "Nortão de Goiás”, limítrofe com o sul do Pará.

\section{Região Nordeste}

Fluxos de origem: a circulação intraestadual representa 39,5\% do movimento total, $35,1 \%$ do movimento com carga e $46,5 \%$ do movimento vazio. São Paulo como origem aparece com $10,2 \%$ do movimento total, $12,5 \%$ do movimento com carga e $6,6 \%$ do movimento vazio. A circulação intrarregional representa $31,7 \%$ do movimento total, $31,7 \%$ do movimento com carga e $31,7 \%$ do movimento vazio.

Fluxos de destino: a circulação intraestadual representa 38,01\% do movimento total, $31,1 \%$ do movimento com carga e $51,7 \%$ do movimento vazio. Apenas Sergipe não registra a distribuição intraestadual como o fluxo mais elevado. São Paulo como destino aparece com 9,8\% do movimento total, $11,7 \%$ do movimento com carga e 7,3\% do movimento vazio. A circulação intrarregional representa $30,5 \%$ do movimento total, $28,1 \%$ do movimento com carga e $35,7 \%$ do movimento vazio.

Circulação intrarregional + inter-regional contígua (fluxos incluídos entre os três principais de origem e destino em todos os movimentos): bidirecionais ( $\mathrm{SE} \leftrightarrow \mathrm{AL} / 4$, $\mathrm{BA} \leftrightarrow \mathrm{PE} / 2, \mathrm{~PB} \leftrightarrow \mathrm{PE} / 2, \mathrm{~PB} \leftrightarrow \mathrm{RN} / 2$ e $\mathrm{PI} \leftrightarrow \mathrm{MA} / 2)$ e unidirecionais $[\mathrm{MG} \rightarrow \mathrm{BA} / 1$ e $\mathrm{BA} \rightarrow \mathrm{MG} / 1$ ], [SE $\rightarrow \mathrm{BA} / 3$ e $\mathrm{BA} \rightarrow \mathrm{SE} / 2$ ], $[\mathrm{BA} \rightarrow \mathrm{AL} / 1$ e $\mathrm{AL} \rightarrow \mathrm{BA} / 1],[\mathrm{BA} \rightarrow \mathrm{PE} / 2$ e $\mathrm{PE} \rightarrow \mathrm{BA} / 2$ ], $[\mathrm{CE} \rightarrow \mathrm{BA} / 2$ e $\mathrm{BA} \rightarrow \mathrm{CE} / 1],[\mathrm{BA} \rightarrow \mathrm{PI} / 1$ e $\mathrm{PI} \rightarrow \mathrm{BA} / 1],[\mathrm{SE} \rightarrow \mathrm{AL} / 1$ e $\mathrm{AL} \rightarrow \mathrm{SE} / 1],[\mathrm{AL} \rightarrow \mathrm{PE} / 2 \mathrm{e}$ $\mathrm{PE} \rightarrow \mathrm{AL} / 2],[\mathrm{PE} \rightarrow \mathrm{PB} / 2$ e $\mathrm{PB} \rightarrow \mathrm{PE} / 2],[\mathrm{PE} \rightarrow \mathrm{RN} / 2$ e $\mathrm{RN} \rightarrow \mathrm{PE} / 3],[\mathrm{PE} \rightarrow \mathrm{CE} / 3$ e $\mathrm{CE} \rightarrow \mathrm{PE} / 2]$, $[\mathrm{CE} \rightarrow \mathrm{PI} / 2$ e $\mathrm{PI} \rightarrow \mathrm{CE} / 1]$, [MA $\rightarrow \mathrm{PI} / 2$ e $\mathrm{PI} \rightarrow \mathrm{MA} / 1],[\mathrm{MA} \rightarrow \mathrm{GO} / 1]$ e $[\mathrm{TO} \rightarrow \mathrm{MA} / 1]$. Fica evidente a força dos fluxos, seja como origem ou destino, de Bahia, Pernambuco e Ceará, os três Estados nordestinos mais industrializados. 


\section{Região Centro-Oeste}

A análise precisa levar em consideração a força do agronegócio, principalmente dos fluxos do binômio milho-soja e do complexo carne, elevados em volume e tonelagem e intensos do ponto de vista intraestadual, intrarregional e inter-regionais - nestes últimos sobretudo com o porto de Santos e Paranaguá.

Fluxos de origem: a circulação intraestadual representa $42,2 \%$ do movimento total, $34,8 \%$ do movimento com carga e $56,7 \%$ do movimento vazio, lembrando, ainda, que não houve posto de coleta no Distrito Federal. São Paulo como destino aparece com $19,2 \%$ do movimento total, $20,5 \%$ do movimento com carga e $16,4 \%$ do movimento vazio. A circulação intrarregional representa $8,6 \%$ do movimento total, $7,4 \%$ do movimento com carga e $11,06 \%$ do movimento vazio.

Fluxos de destino: a circulação intraestadual representa 29,6\% do movimento total, $37,5 \%$ do movimento com carga e $51 \%$ do movimento vazio. São Paulo como origem aparece com $18,2 \%$ do movimento total, $21,4 \%$ do movimento com carga e $13,04 \%$ do movimento vazio. A circulação intrarregional representa $8,7 \%$ do movimento total, $8,04 \%$ do movimento com carga e $9,9 \%$ do movimento vazio.

Circulação intrarregional + inter-regional contígua (fluxos incluídos entre os três principais de origem e destino em todos os movimentos): bidirecionais [MT $\leftrightarrow \mathrm{MS} / 1$ ] e unidirecionais $[\mathrm{DF} \rightarrow \mathrm{MG} / 3$ e $\mathrm{MG} \rightarrow \mathrm{DF} / 2],[\mathrm{DF} \rightarrow \mathrm{GO} / 3$ e $\mathrm{GO} \rightarrow \mathrm{DF} / 1],[\mathrm{GO} \rightarrow \mathrm{MG} / 1$ e $\mathrm{MG} \rightarrow \mathrm{GO} / 1$ ], [MS $\rightarrow \mathrm{MT} / 1$ ] e [MS $\rightarrow \mathrm{PR} / 1$ e $\mathrm{PR} \rightarrow \mathrm{MS} / 3$ ). Fica evidente a força dos fluxos inter-regionais com Minas Gerais e Paraná.

\section{Região Sudeste}

Fluxos de origem: a circulação intraestadual representa $35,9 \%$ do movimento total, $28,1 \%$ do movimento com carga e $52,6 \%$ do movimento vazio. São Paulo como destino aparece com $15,08 \%$ do movimento total, $11,01 \%$ do movimento com carga e $23,7 \%$ do movimento vazio. A circulação intrarregional representa 20,04\% do movimento total, $20,1 \%$ do movimento com carga e $19,7 \%$ do movimento vazio.

Fluxos de destino: a circulação intraestadual representa $36,1 \%$ do movimento total, $29,4 \%$ do movimento com carga e $48,9 \%$ do movimento vazio. São Paulo como origem aparece com $14,8 \%$ do movimento total, $12,5 \%$ do movimento com carga e $18,7 \%$ do movimento vazio. A circulação intrarregional representa $20,1 \%$ do movimento total, $21,07 \%$ do movimento com carga e $18,3 \%$ do movimento vazio.

Circulação intrarregional + inter-regional contígua (fluxos incluídos entre os três principais de origem e destino em todos os movimentos): bidirecionais [SP $\leftrightarrow \mathrm{MG} / 6$, $\mathrm{RJ} \leftrightarrow \mathrm{MG} / 6$ e $\mathrm{RJ} \leftrightarrow \mathrm{ES} / 1$ ] e unidirecionais [SP $\rightarrow \mathrm{ES} / 3$ e $\mathrm{ES} \rightarrow \mathrm{SP} / 3$ ], [RJ $\rightarrow \mathrm{ES} / 3$ e $\mathrm{ES} \rightarrow \mathrm{RJ} / 2$ ], $[\mathrm{SP} \rightarrow \mathrm{RJ} / 3$ e $\mathrm{RJ} \rightarrow \mathrm{SP} / 2$ ], [GO $\rightarrow \mathrm{SP} / 1]$, [SP $\rightarrow \mathrm{PR} / 2$ e $\mathrm{PR} \rightarrow \mathrm{SP} / 1$ ] e [RS $\rightarrow \mathrm{SP} / 1]$. Notam-se as ligações inter-regionais de São Paulo com as regiões Sul e Centro-Oeste.

\section{Região Sul}

Fluxos de origem: a circulação intraestadual representa $51,1 \%$ do movimento total, $43,5 \%$ do movimento com carga e $65,9 \%$ do movimento vazio. São Paulo como destino aparece com 10,9\% do movimento total, $12,6 \%$ do movimento com carga e $7,7 \%$ do movimento vazio. A circulação intrarregional representa $17,5 \%$ do movimento total, $17,8 \%$ do movimento com carga e $16,9 \%$ do movimento vazio.

Fluxos de destino: a circulação intraestadual representa 54,08\% do movimento total, $47,5 \%$ do movimento com carga e $67,9 \%$ do movimento vazio. São Paulo como origem 
aparece com $11,5 \%$ do movimento total, $13,3 \%$ do movimento com carga e $8,3 \%$ do movimento vazio. A circulação intrarregional representa 18,5\% do movimento total, $19,4 \%$ do movimento com carga e $16,8 \%$ do movimento vazio.

Circulação intrarregional + inter-regional contígua (fluxos incluídos entre os três principais de origem e destino em todos os movimentos): bidirecionais [PR $\leftrightarrow \mathrm{SC} / 6] \mathrm{e}$ unidirecionais $[\mathrm{RS} \rightarrow \mathrm{PR} / 3$ e $\mathrm{PR} \rightarrow \mathrm{RS} / 3],[\mathrm{PR} \rightarrow \mathrm{SP} / 3$ e $\mathrm{SP} \rightarrow \mathrm{PR} / 3],[\mathrm{SC} \rightarrow \mathrm{SP} / 3$ e $\mathrm{SP} \rightarrow \mathrm{SC} / 3]$ e $[\mathrm{RS} \rightarrow \mathrm{SP} / 3$ e $\mathrm{SP} \rightarrow \mathrm{RS} / 3$ ]. Aqui ficam evidenciados a fortíssima ligação intrarregional e os fluxos com São Paulo.

Um panorama geral da circulação do TRC no território nacional, separado por modalidade de movimento (Quadro 4), é bastante elucidativo de uma das principais características do país: as diferenças regionais. Desequilíbrio entre pontos de produção e de consumo, impacto da questão demográfica (rarefação e concentração) e relevância da distância - que no Brasil alcança facilmente os quatro dígitos em circunstâncias intrarregionais e, muitas vezes, até mesmo intraestaduais - são variáveis que impactam diretamente no uso do território.

Quadro 4. Matriz origem-destino por tipo de movimento (em \% da circulação total). Obs.: "Para as regiões Norte, Nordeste, Centro-Oeste e Sul os fluxos inter-regionais incluem os fluxos de e para São Paulo. Para a Região Sudeste, os fluxos intrarregionais incluem os fluxos de e para São Paulo. Fonte: elaboração própria com base na Pesquisa Nacional de Tráfego 2011.

\begin{tabular}{|c|c|c|c|c|c|c|}
\hline \multirow[t]{2}{*}{ O/D } & \multirow[t]{2}{*}{ FLUXO* } & \multicolumn{5}{|c|}{ REGIÃO } \\
\hline & & Norte & Nordeste & $\begin{array}{l}\text { Centro- } \\
\text { Oeste }\end{array}$ & Sudeste & Sul \\
\hline \multicolumn{7}{|c|}{ MOVIMENTO TOTAL (COM CARGA + VAZIO) } \\
\hline \multirow[t]{4}{*}{ OR } & intraestadual & 25,5 & 39,5 & 42,2 & 35,9 & 51,1 \\
\hline & intrarregional & 11,3 & 31,7 & 8,6 & 20,04 & 17,5 \\
\hline & inter-regional & 63,2 & 28,8 & 49,2 & 44,06 & 31,4 \\
\hline & São Paulo & 18,9 & 10,2 & 19,2 & 15,08 & 10,9 \\
\hline \multirow[t]{4}{*}{$\mathrm{DE}$} & intraestadual & 22,1 & 38,01 & 29,6 & 36,1 & 54,08 \\
\hline & intrarregional & 7,9 & 30,5 & 8,7 & 20,1 & 18,5 \\
\hline & inter-regional & 70,0 & 31,4 & 64,7 & 43,8 & 27,4 \\
\hline & São Paulo & 22,5 & 9,8 & 18,2 & 14,8 & 11,5 \\
\hline \multicolumn{7}{|c|}{ MOVIMENTO COM CARGA } \\
\hline \multirow[t]{4}{*}{ OR } & intraestadual & 22,02 & 35,1 & 34,8 & 28,01 & 43.5 \\
\hline & intrarregional & 8,4 & 31,7 & 7,4 & 20,1 & 17,8 \\
\hline & inter-regional & 69,5 & 33,2 & 57,8 & 51,8 & 25,7 \\
\hline & São Paulo & 20,9 & 12,5 & 20,5 & 11,01 & 12,6 \\
\hline \multirow[t]{4}{*}{$\mathrm{DE}$} & intraestadual & 14,6 & 31,1 & 37,5 & 29,4 & 47,5 \\
\hline & intrarregional & 5,8 & 28,1 & 8,04 & 21,07 & 19,4 \\
\hline & inter-regional & 79,6 & 40,8 & 54,4 & 49,5 & 33,1 \\
\hline & São Paulo & 27,03 & 11,7 & 21,4 & 12,5 & 13,3 \\
\hline \multicolumn{7}{|c|}{ MOVIMENTO VAZIO } \\
\hline \multirow[t]{4}{*}{ OR } & intraestadual & 32,5 & 46,5 & 56,7 & 52,6 & 65,9 \\
\hline & intrarregional & 10,7 & 31,7 & 11,06 & 19,7 & 16,9 \\
\hline & inter-regional & 56,8 & 21,8 & 32,2 & 27,7 & 17,2 \\
\hline & São Paulo & 14,2 & 6,6 & 16,4 & 23,7 & 7,7 \\
\hline \multirow[t]{4}{*}{$\mathrm{DE}$} & intraestadual & 46,3 & 51,7 & 51,0 & 48,9 & 67,9 \\
\hline & intrarregional & 15,2 & 35,7 & 9,9 & 18,3 & 16,8 \\
\hline & inter-regional & 38,5 & 12,6 & 39,1 & 32,8 & 15,3 \\
\hline & São Paulo & 8,06 & 7,3 & 13,04 & 18,7 & 8,3 \\
\hline
\end{tabular}


Os números evidenciam algumas situações que merecem destaque - embora, muitas vezes, seja um exercício complicado compreendê-los em sua totalidade, levando-se em conta a complexidade da formação socioespacial brasileira. Vejamos os fluxos intraestaduais, bastante expressivos em qualquer dinâmica regional de circulação. Aqui fica claro o fato de que a distribuição intraestadual é realizada na escala T2/D, em que as rotas de distribuição têm origem nas capitais e outras cidades intermediárias (como Petrolina/PE, Bauru/SP, Catalão/GO, Marabá/PA e Santa Maria/RS, por exemplo) para suprir as cidades menores e menos relevantes do ponto de vista econômico - um movimento geralmente realizado por TACs agregados em um esquema que se parece com "linhas regulares de ônibus", mas com o caminhão vazio na volta na maioria das vezes.

No Norte, o percentual dos fluxos intraestaduais é menor se comparado com outras regiões, mas, na nossa perspectiva, a sua extensa circulação hidroviária rebaixa os números do TRC. Sul e Sudeste, as regiões mais ricas do Brasil, possuem fluxos intraestaduais equilibrados de origem e destino em todos os movimentos, fato que pode denotar o peso econômico de seu interior, que acaba configurando mercados que vão além da conhecida concentração nas capitais e/ou regiões metropolitanas.

A importância de São Paulo na circulação rodoviária nacional é explícita, já que nenhum outro ente federativo alcança níveis de participação na mesma proporção em âmbito nacional. Mesmo assim, este indicativo varia de 6,6\% a 27,03\%, denotando muitos tipos de situação. Dessa forma, São Paulo é um destino que todas as empresas almejam; ao mesmo tempo, é o principal polo emissor de cargas do país, em um movimento diário de sístole e diástole de caminhões de todos os tipos e com toda a sorte de carga de e para inúmeros pontos do país. Portanto, em São Paulo os fluxos $\mathrm{T} 1$, majoritariamente de longo curso, adquirem uma magnitude muito valiosa para os agentes da circulação, sobretudo para os autônomos independentes.

Quanto aos fluxos intrarregionais, percebe-se a baixa incidência nas regiões Norte e Centro-Oeste. Fator totalmente compreensível se levarmos em conta a conjugação entre fraca produção industrial (com exceção do Pólo Industrial de Manaus e das regiões metropolitanas de Belém e Goiânia), rarefação demográfica, mercados consumidores pequenos e muito esparramadas pelo território. É nesta porção do país - que corresponde a 5,48 milhões $\mathrm{km}^{2}$, ou $64 \%$ do território nacional, mas com apenas $15,6 \% \mathrm{da}$ população brasileira (Censo 2010) - que a variável distância atinge o seu ápice em relação ao custo-benefício do serviço de transporte.

O destaque fica para a Região Nordeste (1,55 milhão $\mathrm{km}^{2}$, ou 18,2\% do território nacional, que concentram $27,8 \%$ da população brasileira), que apresenta os maiores índices de fluxos intrarregionais (entre $28,1 \%$ e $35,7 \%$ ) do país. Este elemento provavelmente indica uma acentuada produção de bens manufaturados e agropecuários de cunho regional, ligados à cultura do nordestino em vários aspectos (gastronomia, vestuário, ferramentas etc). Ademais, a relação mais equilibrada entre fluxos intrarregionais e inter-regionais também é evidenciada no Nordeste, denotando trocas intensas com outras partes do país, sobretudo a partir do feixe litorâneo de capitais entre Natal e Salvador.

Do ponto de vista inter-regional, Norte e Centro-Oeste apresentam altíssimos índices, cuja explicação equivale, sob o nosso ponto de vista, aos fracos mercados locais e regionais, gerando uma dependência excessiva, seja na origem ou no destino, dos mercados mais longínquos. Para o Centro-Oeste, entretanto, a análise precisa levar em consideração o agronegócio, que depende muito das outras regiões tanto para realizar o escoamento de sua produção quanto o fornecimento de insumos. É interessante que nas regiões Sul e Sudeste (somadas, as duas regiões correspondem a 1,50 milhão km², ou $17,7 \%$ do território nacional, que concentram $56,6 \%$ da população brasileira) os 
fluxos inter-regionais ultrapassam os intrarregionais em todos os movimentos (com a exceção do Sul como destino no movimento caminhão vazio), o que denota a concentração dos maiores centros de produção e consumo do país em distâncias médias, um custo-benefício altíssimo para o modal rodoviário.

Um panorama dos 51 principais fluxos (acima de mil caminhões) dentre os 729 movimentos totais (soma de caminhões cheios e vazios) do país oferecidos pela PNT apenas serve para corroborar alguns fenômenos já expostos. O peso de São Paulo como grande relê de distribuição é expresso em 14 movimentos de origem (destinos: Sul, Sudeste/1, Centro-Oeste/4, Nordeste/4 e Norte/2) e 10 de destino (origem: Sul/3, Sudeste/1, Centro-Oeste/3, Nordeste/2 e Norte/1). A relevância dos movimentos intraestaduais aparece em 17 fluxos (Sul/3, Sudeste/3, Centro-Oeste/3, Nordeste/7 e Norte/1), enquanto a importância dos intrarregionais, em 9 fluxos (Sul/5, Sudeste/2 e Nordeste/2). O último fluxo de destaque dentre os 51 mais intensos é o inter-regional Centro-Oeste $\rightarrow$ Sul, que certamente expressa as grandes tonelagens de soja e milho rumo ao porto de Paranaguá.

\section{Frete-retorno, um indicador de desajuste territorial}

Uma das variáveis do TRC que melhor enquadram o desequilíbrio entre pontos de consumo, de produção e na relação entre ambos é o frete-retorno, um problema a ser enfrentado por todos os agentes. Na carga lotação e em alguns tipos de carga (especial e de grande porte e granéis líquidos químicos, por exemplo), a volta vazia é embutida parcialmente no valor total do frete no caso de empresas transportadoras.

Para autônomos independentes, raramente há contemplação do frete-retorno; para ele, a ida geralmente é carga lotação, e a volta é vazia ou com alguma carga picada obtida ao longo do caminho. "A gente volta pegando o que tem", revelou um autônomo gaúcho em São Raimundo Nonato, no interior do Piauí, enquanto descarregava uma carga de móveis de escritório oriunda de São Paulo. ${ }^{5}$ Para autônomos agregados que operam fluxos T1, a situação é a mesma. Para aqueles que operam fluxos T2, o retorno geralmente é vazio, mas podem ser realizados pequenos carretos se não houver comprometimento da programação preestabelecida pelo subcontratante.

Nossa pesquisa apontou que nos nodais - entendidos como a expressão territorial mais elevada do TRC pela densidade de fixos e pela frequência, qualidade e intensidade dos fluxos - são maiores as possibilidades de obtenção de frete-retorno, mas, mesmo assim, limitadas diante da elevada oferta de serviços de transporte (Huertas, 2013). Mesmo no Estado de São Paulo, o de maior movimento do país, a ocorrência de fluxos com caminhões vazios é de $46 \%$ do total (Estado de São Paulo, 2006), enquanto a média mundial fica entre $15 \%$ e $25 \%$ (Silveira, 2009). Mas o problema principal é o excesso de oferta ao qual nos referimos ou a má distribuição da demanda? Por qual motivo, segundo dados de Francisco Pontes, consultor técnico do Sindicato das Empresas de Transportes de Carga e Logística no Estado do Ceará (Setcarce), ${ }^{6}$ o fluxo Nordeste (A)-(B) Sul/Sudeste é em média de $40 \%$ a $50 \%$ menor, respectivamente para ETCs e subcontratados, em relação ao fluxo inverso (B-A)? De qualquer modo, o frete-retorno torna-se um indicativo do desenvolvimento desigual e combinado.

Além disso, o desbalanceamento verificado leva a uma situação conflituosa entre ETCs e TACs, pois todos precisam voltar o quanto antes para girar a frota, obter outro carregamento e, assim, completar o ciclo. A pesquisa Caminhoneiros do Brasil - Autônomos e Empregados de Frota (CNT, Sest e Senat, 2013) revelou que respectivamente 80,1\% dos caminhões de empresa e 75,9\% dos veículos de autônomos rodam vazios em algum momento, sendo que este índice chega a quase $30 \%$ de toda a quilometragem rodada para ambos os agentes.
5. Depoimento concedido ao autor em 02 out. 2011 no centro de São Raimundo Nonato (PI).

6. Entrevista concedida ao autor em 26 set. 2011 em Fortaleza. 
Um autônomo baiano quando está indo para a Bahia vindo de São Paulo raciocina em termos de frete-retorno. "Eu não carrego com nenhum autônomo local de lá para cá, pois ele me cobraria $\mathrm{R} \$ 3,5$ mil, enquanto pago $\mathrm{R}$ \$ 2,5 mil a carreta com autônomo do Sul e do Sudeste", explicou Márcio Andrade, gerente da Rotrans Transportes e Serviços ${ }^{7}$ (transportadora sediada em Feira de Santana/BA), evidenciando o fato. O mesmo ocorre com a Rapidão Cometa, ${ }^{8}$ que na sua escala de atuação originária e preferencial (a Região Nordeste) opta por subcontratar TACs e pequenas ETCs para fluxos T2, enquanto em boa parte da operação de suas linhas nacionais (fluxos T1) subcontrata ETCs das regiões Sul e Sudeste, como nos explicou o gerente de frota da empresa.

Este fato merece uma ampla pesquisa no campo da sociologia do trabalho, pois é preciso admitir que a distribuição da oferta de serviço de transporte rodoviário no Brasil é desequilibrada, mas no caso específico dos autônomos a volta para a sua residência com alguma frequência é um fator emocional difícil de ser mensurado, e de certo modo embaça a equação entre oferta e demanda. Esta questão ganha novos conteúdos territoriais no caso do escoamento da safra agrícola do Centro-Oeste, cujos fluxos de retorno são mais intensos e equalizados, embora o valor pago esteja em um patamar bastante inferior na comparação com a ida. Primeiro é necessário destacar que frete-retorno, no agronegócio, em grande parte é matéria-prima para adubo, que o país importa em grandes quantidades, pois a produção nacional de macronutrientes (nitrogênio, fósforo e potássio, que misturados compõem o complexo NHK) é pequena.

Paulínia, Cubatão, Antonina (PR) e Paranaguá (50\% do total) são os principais pontos de coleta de matéria-prima de adubo. Calcário, utilizado em grande escala para a calagem (correção da acidez do solo), com carregamento em pontos próximos às jazidas (Cajati/SP, Arcos/MG, Araxá/MG, Formiga/MG e Catalão/GO, por exemplo), e o chamado sal boiadeiro, cujo centro logístico é Mossoró (RN), também são opções de frete-retorno. Em todos os casos verifica-se uma sazonalidade que impacta o TRC. Calcário e fertilizantes precisam estar disponíveis para o preparo do solo no plantio (segundo semestre); em quantidades menores ao longo da safra para a sua manutenção e na entressafra para a sua recuperação. O sal é mais solicitado em períodos de estiagem, quando a pastagem fica mais rala e seca.

Mas por qual motivo o frete-retorno é mais barato (Quadro 5)? No caso de bens de consumo, há um descompasso nos fluxos em termos de oferta e procura por serviço de transporte, e o mesmo pode ser dito em parte para a carga agrícola, pois a demanda pelos insumos é muito elevada.

Quadro 5. Desajuste de frete-retorno. Data de referência (28 maio 2012) - base bitrem (37 mil kg). Obs.: 1.Soja a granel e adubo; 2.Geralmente frete-retorno para Goiânia; 3.Farelo de soja e adubo. Fonte: Brasil Central, Bergamaschi e Coptrans.

\begin{tabular}{|c|c|c|c|c|c|}
\hline Origem & Destino & $\begin{array}{c}\text { Distância } \\
\text { (em km) }\end{array}$ & $\begin{array}{c}\text { Frete de ida } \\
\text { (R\$̦/ton) }\end{array}$ & $\begin{array}{c}\text { Frete-retorno } \\
\text { (Rș/ton) }\end{array}$ & $\begin{array}{c}\text { Desajuste } \\
(\text { em \%) }\end{array}$ \\
\hline Rondonópolis ${ }^{1}$ & Cambé (PR) & 1.190 & 90 & 40 & -225 \\
\hline Rondonópolis ${ }^{1}$ & Paranaguá & 1.600 & 140 & 92 & -152 \\
\hline Rio Verde ${ }^{1}$ & Paranaguá & 1.300 & 110 a 125 & 100 & $-110 \mathrm{a}-125$ \\
\hline Rio Verde $^{1}$ & Santos & 1.050 & 110 a 125 & 80 & $-137 a-156$ \\
\hline Rio Verde ${ }^{1}$ & Uberlândia $^{2}$ & 355 & 45 a 50 & 30 & -150 a -166 \\
\hline \multirow[t]{4}{*}{ Rondonópolis ${ }^{3}$} & Chapecó & 1.500 & 3,40 & 2,00 & -170 \\
\hline & Maringá & 1.100 & 3,09 & & -154 \\
\hline & Paranaguá & 1.600 & 3,12 & & -156 \\
\hline & Santos & 1.450 & 3,37 & & -168 \\
\hline
\end{tabular}

Para Celso Panerari, gerente de Logística da filial de Cambé (PR) da Transportes 1500, já há uma cultura de longo tempo por parte do embarcador que enxerga este frete como
7. Entrevista concedida ao autor em o8 dez. 2011 em Feira de Santana (BA) 8. Em maio de 2012 a Rapidão Cometa foi adquirida pela estadunidense Federal Express (FedEx). 
retorno e naturalmente o rebaixa. Mas as empresas transportadoras encontraram um subterfúgio para ao menos amenizar o desequilíbrio: com a garantia de obtenção de frete-retorno, quando acertado na origem do frete de ida, priorizam o uso de sua frota própria, em detrimento da subcontratação de transportadoras menores e autônomos, sobretudo na entressafra.

Luiz Fernando Alves Dall Orsoleta, gerente da filial de Rondonópolis (MT) da Cooperativa de Transportes 14 de Dezembro (Coptrans), aponta a ociosidade da frota própria (cooperados) em torno de 20\% a partir de Paranaguá. Mesmo quando há entrega de milho e farelo de soja no Oeste Catarinense, o caminhoneiro roda vazio até o porto paranaense para em seguida buscar insumo de adubo. "De Paranaguá ninguém volta vazio", afirmou, enquanto Cubatão e Paulínia agem como frete-retorno de Santos.

Em Paranaguá detectamos que há um movimento de curta distância (um raio de 10 $\mathrm{km}$ ) entre a coleta da matéria-prima de adubo nos terminais e as unidades misturadoras (Bunge, Heringer, Mosaic e Fospar são as maiores) operado por autônomos com veículos velhos e filiados à Cooperativa de Transporte de Cargas e Anexos Ltda. (Coopanexos), que organiza este fluxo. Segundo um caminhoneiro, este frete paga entre R\$ 7 e R $\$ 10$ a tonelada, e 30\% ficam com o sindicato. É um movimento de 24 horas, e cada autônomo realiza de 2 a 3 viagens por dia.

Mas o conflito que envolve diretamente o frete-retorno também existe entre ETCs, como nos explicou Carlos Denis Rodrigues, gerente comercial da capixaba Belmok. Para retornar cheio ao Espírito Santo - 90\% da carga que a empresa distribui no Estado é originada em São Paulo -, a Belmok tem como frete de ida mercadorias importadas pelo porto de Vitória e carga industrial local (Ducoco, Weg, Michelin e Del Valle). Ocorre, entretanto, que esta carga é frete-retorno para as grandes ETCs paulistas - a Braspress, por exemplo, tem um centro de distribuição em Serra (ES) que consolida cargas de São Paulo, Rio e Belo Horizonte para o Nordeste. "Ele está roubando, como carga de retorno, a carga de ida da Belmok para São Paulo."

Diante da escassez de dados disponíveis, fica comprometida a comprovação quantitativa do desajuste do frete-retorno do ponto de vista tanto nacional quanto regional. "Trago 10 carretas cheias de São Paulo e nove voltam vazias, mas isso é em nível de Brasil”, afirmou um empresário ligado à Federação do Transporte de Cargas do Estado do Rio de Janeiro (Fetranscarga), apresentando uma evidência numérica do desequilíbrio em questão. O gerente da Rapidão Cometa revela uma relação desigual de 5 para 1 na rota São Paulo-Rio (de cada 5 caminhões cheios com origem na capital paulista, apenas um retorna cheio) e de 3 para 1 nas rotas Su/Sudeste-Nordeste.

A partir da base da PNT 2011, foi possível estabelecer um índice de equilíbrio (vide abaixo) para a composição dos fluxos (Quadro 6): quanto mais próximo de 1, mais equilibrado é o movimento total, ou seja, mais equilibrada a relação entre caminhões cheios e caminhões vazios.

$$
\text { Índice de equilíbrio }=\frac{\text { origem com carga }+ \text { destino com carga }}{\text { origem (carga+vazio })+ \text { destino (carga+vazio) }}
$$

O fluxo total (FT) leva em conta todo o movimento, o fluxo 1 (F1) representa apenas os fluxos interestaduais (T1/A e T1/B) e o fluxo 2 (F2), os intraestaduais (T1/C e T2). Como não fora instalado posto de coleta no Distrito Federal, Roraima e Amazonas, o índice para fluxos intraestaduais é zero, como detectado na pesquisa. No Amapá, cujo índice é 1 (equilíbrio perfeito), provavelmente houve algum engano 
na coleta ou transcrição dos dados, pois o Estado também não recebeu posto, fato que inviabiliza a captação de fluxos intraestaduais. Por esse motivo trocaremos o índice 1 por zero.

Quadro 6. Índice de equilíbrio de fluxos. Fonte: elaboração própria com base na Pesquisa Nacional de Tráfego 2011

\begin{tabular}{|l|c|c|c|c|}
\hline UF & FT & F1 & F2 & \\
\hline AC & 0,564 & 0,641 & 0,344 & $-46,35 \%$ \\
\hline AL & 0,622 & 0,664 & 0,539 & $-18,80 \%$ \\
\hline AM & 0,749 & 0,749 & 0,000 & 0 \\
\hline AP & 0,633 & 0,630 & 0,000 & 0 \\
\hline BA & 0,649 & 0,601 & 0,562 & $-06,48 \%$ \\
\hline CE & 0,687 & 0,739 & 0,571 & $-22,71 \%$ \\
\hline DF & 0,679 & 0,679 & 0,000 & 0 \\
\hline ES & 0,625 & 0,728 & 0,534 & $-26,67 \%$ \\
\hline GO & 0,666 & 0,711 & 0,522 & $-26,65 \%$ \\
\hline MA & 0,658 & 0,702 & 0,578 & $-17,75 \%$ \\
\hline MG & 0,644 & 0,720 & 0,584 & $-18,83 \%$ \\
\hline MS & 0,565 & 0,664 & 0,478 & $-28,03 \%$ \\
\hline MT & 0,666 & 0,756 & 0,591 & $-21,84 \%$ \\
\hline PA & 0,772 & 0,793 & 0,570 & $-28,14 \%$ \\
\hline PB & 0,574 & 0,625 & 0,485 & $-22,39 \%$ \\
\hline PE & 0,623 & 0,680 & 0,470 & $-30,92 \%$ \\
\hline PI & 0,630 & 0,663 & 0,577 & $-13,03 \%$ \\
\hline PR & 0,658 & 0,717 & 0,599 & $-16,47 \%$ \\
\hline RJ & 0,686 & 0,753 & 0,590 & $-21,58 \%$ \\
\hline RN & 0,624 & 0,701 & 0,533 & $-23,92 \%$ \\
\hline RO & 0,646 & 0,551 & 0,518 & $-05,94 \%$ \\
\hline RR & 0,737 & 0,737 & 0,000 & 0 \\
\hline RS & 0,636 & 0,816 & 0,519 & $-36,43 \%$ \\
\hline SC & 0,645 & 0,726 & 0,556 & $-23,44 \%$ \\
\hline SE & 0,658 & 0,679 & 0,577 & $-15,04 \%$ \\
\hline SP & 0,691 & 0,756 & 0,367 & $-51,43 \%$ \\
\hline TO & 0,586 & 0,651 & 0,475 & $-27,02 \%$ \\
\hline Brasil & 0,650 & 0,697 & 0,527 & $-23,90 \%$ \\
\hline
\end{tabular}

Os números mostram que os fluxos totais origem-destino (FT) em relação ao Amazonas estão entre os mais equilibrados do país por causa da grande distância em relação a São Paulo (cerca de $4 \mathrm{mil} \mathrm{km}$ ) e da intermodalidade, que acarreta no pagamento do frete da balsa Belém-Manaus e de taxas portuárias. Em outras palavras: sem um equacionamento mínimo nas rotas para Manaus, o movimento torna-se inviável. Como acreditamos que boa parte dos dados relativos ao Pará referem-se na prática ao Amazonas (o caminhão embarca na balsa rumo a Manaus após transferência em Belém), os índices de equilíbrio para o Pará também figuram entre os melhores do Brasil. O mesmo vale para Roraima, cujo fluxo segue via BR-174 após o transbordo fluvial pelo rio Amazonas. Logo em seguida aparecem São Paulo, Ceará, Rio de Janeiro e Distrito Federal.

Em relação aos fluxos interestaduais (F1), Rio Grande do Sul, Pará, São Paulo, Mato Grosso, Rio de Janeiro e Amazonas estão entre os mais equilibrados; o mesmo vale para Paraná, Mato Grosso, Rio de Janeiro, Minas Gerais e Maranhão no que diz respeito aos fluxos intraestaduais (F2).

Neste item São Paulo tem o segundo pior índice, mas uma observação importante precisa ser feita. Como a pesquisa envolveu coleta de dados apenas em rodovias federais, 
a captação dos fluxos F2 para São Paulo fica distorcida por causa da elevada presença de rodovias estaduais em seu território. Fluxos entre Santos, Campinas, Ribeirão Preto e São José do Rio Preto, citando alguns exemplos, ficaram ausentes por não trafegarem em BRs.

Além disso, chama bastante atenção o maior desequilíbrio de fluxos F2 na comparação com fluxos F1. Em outras palavras, é maior a quantidade de caminhões vazios rodando com origem e destino no mesmo Estado do que veículos que operam com origem e destino entre diferentes Unidades da Federação - média nacional de 23,90\%.

É fato que os desequilíbrios geram retornos vazios e, consequentemente, acréscimo nos custos rodoviários (estes são diretamente proporcionais à distância percorrida: $1,13 \%$ para $50 \mathrm{~km}, 7,46 \%$ para $400 \mathrm{~km} ; 12,47 \%$ para $800 \mathrm{~km} ; 22,57 \%$ para 2,4 mil $\mathrm{km}$ e $29,82 \%$ para 6 mil km, segundo cálculos da NTC para frete-peso) ${ }^{9}$ e comprometimento da diluição dos custos fixos. "Se $\mathrm{r}=0$ (todas as viagens de retorno vazias), $\mathrm{f}=2$, ou seja, dobra-se o custo rodoviário, devido à duplicação do percurso. Se $\mathrm{r}=1$ (todas as viagens de retorno carregadas), $\mathrm{f}$ (frete-peso) $=1$, ou seja, não haverá alteração no valor de B (custo de transferência por t. km)". ${ }^{10}$

Diante dessa crônica situação de desequilíbrio de fluxos no Brasil, perfeitamente relacionada à divisão territorial do trabalho, o mercado entende a ocorrência do freteretorno apenas no sentido de menor fluxo de uma rota (que pode ser A-B ou B-A). Em outras palavras, quanto menor o fluxo, mais baixo o valor do frete. Nas regiões Norte, Nordeste e Centro-Oeste os fluxos são mais desequilibrados, e o problema do frete-retorno se agrava. De modo geral, verifica-se ainda no Brasil que ligações no sentido norte-sul (longitudinais) registram fluxos mais equalizados, caso contrário das ligações leste-oeste (latitudinais).

Para tentar amenizar a situação, Paulo Vicente Caleffi, presidente da Federação das Empresas de Logística e Transporte de Cargas do Rio Grande do Sul (Fetransul), ${ }^{11}$ apregoa a busca do empresariado por um ponto de equilíbrio para a carga de retorno - mas difícil de ser obtido, na nossa opinião. Para ele, o “ônus não pode ser repassado ao autônomo e nem à transportadora, e o embarcador precisa saber que onde não há contra-fluxo precisa pagar por ele." A obtenção de clientes duradouros, com contratos de médio e longo prazos, e operações mais intensas em praças com retorno cativo são medidas engendradas pelos agentes do circuito superior para evitar a ociosidade da frota no retorno.

Mas um fenômeno é observado no fluxo entre São Paulo e a Região Sul, teoricamente um frete-retorno para ETCs e motoristas autônomos paranaenses, catarinenses e gaúchos. O desequilíbrio em termos de valor de frete é comparável ao verificado na relação entre regiões mais e menos desenvolvidas - segundo alguns carreteiros, um dos piores do país -, mas no caso em questão se trata de zonas com bastante produção e consumo. Por isso mesmo que as empresas transportadoras acabam dominando o mercado (praças com retorno cativo), e a carga sobrante para os autônomos registram cifras rebaixadas de frete-retorno por conta da altíssima oferta de agentes.

Outra estratégia das grandes ETCs é equacionar o frete-retorno, dando prioridade na relação $r=1 \backslash f=1$ para caminhões de sua frota. Nas relações $r=0 \backslash f=2$, ou próximas dela, opta-se pela subcontratação de ETCs menores ou de TACs. Nesse caso, o circuito inferior arca com a carência do contra-fluxo. Recentemente, algumas transportadoras de grande porte, em consonância com grandes embarcadores, têm desenvolvido um artifício conhecido como compartilhamento de frota com o objetivo de evitar a ociosidade no retorno. Em linhas gerais, após a entrega da carga em centros de distribuição de um cliente, o veículo imediatamente passa a transportar mercadorias de outras empresas. Este artifício, entretanto, só cabe ao circuito superior.
9. In <www.ntc.org.br/retorno_vazio.htm> Acesso em: 05 jan. 2012.

10. Idem, parênteses com grifos nossos.

11. Entrevista concedida ao autor em 04 jul. 2011 em Bento Gonçalves (RS). 


\section{Considerações finais}

Historicamente falando, a produção de pesquisas origem-destino não recebeu importância e tratamento satisfatórios das autoridades brasileiras competentes. Seja por desconhecimento técnico, seja por ausência de vontade política, o fato é que o país está muito distante de uma compreensão mais aprofundada e perene de suas dinâmicas de circulação - em especial do TRC, responsável pela maior fatia da matriz de transportes de carga do país. Não é exagero afirmar que não sabemos com precisão a natureza, origem e destino, frete praticado, valor e tonelagem da carga transportada pelas estradas deste país de dimensão continental e, ainda, por qual agente específico, caminhoneiro autônomo (agregado e/ou independente) ou empresa transportadora.

A PNT 2011 trouxe alguns elementos interessantes, é verdade, além de buscar recuperar um espaço perdido desde o final dos anos 1990. Entretanto, torna-se necessário listar algumas deficiências que poderiam ser corrigidas a fim de incrementar a matriz origem-destino do TRC no país. A coleta de dados limitada a três semanas do ano, em períodos diferenciados, é a primeira limitação constatada, pois não capta com precisão a sazonalidade da economia nacional e de suas particularidades regionais. Certamente existem picos de produção de serviços de transporte observados nos períodos não pesquisados.

A ausência de postos de coleta nos Estados do Amazonas, Roraima e Amapá compromete a captação de seus fluxos intraestaduais pelos motivos já apontados. O mesmo vale para muitos Estados por causa da não cobertura dos fluxos de estradas estaduais, principalmente no caso paulista (de altíssima incidência de SPs em detrimento de BRs), também explicado anteriormente.

A falta de dados constantes e sistematizados, sobretudo em relação aos fluxos, é um dado crônico, mas um fato poderia reverter totalmente esta situação adversa. A adoção do Conhecimento de Transporte Eletrônico (CT-e), obrigatória para todos os agentes do TRC desde dezembro de 2013, proporcionaria a formação de um banco de dados fidedigno e em tempo real como provavelmente nunca houve. Até o momento, entretanto, nenhum órgão competente disponibilizou as informações deste cabedal quantitativo, que poderiam ser estratificadas de diversos modos.

Salientamos ainda que as pesquisas origem-destino não captam a variável operacional do serviço (carga lotação ou fracionada) e as operações de transferência e transbordo de carga, fato que compromete a análise em um país de dimensões continentais e regionalmente bastante desigual. Isso significa que uma carga com origem em Porto Alegre e destino em Natal pode, na pesquisa, apresentar formatos diferentes segundo as transferências ocorridas ao longo do trajeto.

Neste exemplo, se a carga é submetida a transferências em São Paulo e no Recife antes de chegar à capital potiguar, verifica-se uma alteração no seu quadro origem-destino, que passa a ser desmembrado em quatro etapas (Porto Alegre $\rightarrow$ São Paulo $\rightarrow$ Recife $\rightarrow$ Natal) que evidenciam a cadeia de subcontratações. Para que esta situação seja ao menos amenizada - muito provavelmente seja impossível captar esta realidade operacional do TRC na sua totalidade -, os questionários poderiam conter um item específico sobre transferência ou transbordo, cabendo ao motorista informar se houve ou não esta operação e em qual cidade, ou ao entrevistador checar os dados contidos no conhecimento de carga.

Seria muito interessante também repetir uma informação disponibilizada em uma pesquisa lançada pelo IBGE em 1981: as linhas em tráfego das empresas transportadoras com itinerário fixo segundo as Unidades da Federação. Como as linhas podem 
ser municipais, intermunicipais, interestaduais e internacionais, teríamos assim a possibilidade de alcance de um panorama riquíssimo sobre a área de atuação das ETCs, refinando a análise a um nível desejável para a composição dos fluxos (T1 e T2). O órgão federal, naquela ocasião, ainda detectou a extensão (em quilômetros) das linhas.

E como captar o frete-retorno, tido como um índice de desajuste territorial? O roteiro de 14 dias realizado em fevereiro de 2013 pelo autônomo Benedito Aparecido Barbosa, de 58 anos, é bastante elucidativo (Huertas, 2013). Ele saiu de Camanducaia, sua cidade de residência no sul de Minas Gerais, para carregar o seu caminhão (Mercedes 1620 trucado, ano 2010) em São Paulo e descarregar no Recife. A trajetória completa desta jornada envolveu oito etapas:

»Camanducaia/MG $\rightarrow$ São Paulo: $130 \mathrm{~km}$ - vazio;

» São Paulo $\rightarrow$ Campina Grande $\rightarrow$ Recife (via Paulo Afonso/BA e Caruaru/PE): 3,2 mil $\mathrm{km}$ - frete de R\$ 6 mil - 4 mil kg (tornos mecânicos novos);

» Recife $\rightarrow$ Feira de Santana: 800 km - frete de R \$ 1,5 mil - 14 mil kg (tinta);

» Feira de Santana $\rightarrow$ Vitória da Conquista/BA: 1.190 km - vazio;

"Vitória da Conquista/BA $\rightarrow$ Goiânia (via Brumado/BA, Correntina/BA e Brasília): 1,3 mil km - frete de R 1,8 mil - 14 mil kg (polietileno em big bags);

» Goiânia $\rightarrow$ Uberlândia (via Itumbiara/GO e BR-365): 355 km - vazio;

»Uberlândia $\rightarrow$ Pouso Alegre/MG (via Batatais/SP, Itamoji/MG, Muzambinho/MG e Alfenas/MG): $650 \mathrm{~km}$ - frete de R\$ 1 mil - 14 mil kg (farelo de soja);

» Pouso Alegre/MG $\rightarrow$ Camanducaia/MG: 76 km - vazio.

É compreensível entender o frete de ida como São Paulo $\rightarrow$ Recife (embora tenha havido descarregamento de parte da carga em Campina Grande, mas para o mesmo cliente), levando-se em consideração que o veículo rodou vazio de Camanducaia a São Paulo. E o frete-retorno? Esta realidade é muito comum no Brasil, um retorno "picando" que alterna trechos com carga e outros com caminhão vazio, tanto para autônomos quanto para transportadoras. Neste exemplo, se o motorista é abordado para entrevista no trecho (iii), é frete-retorno com origem em Pernambuco e destino na Bahia, e aí por diante.

Queremos demonstrar com isso que é muito difícil captar com total fidedignidade o frete-retorno (e sempre salientando que o que é ida para um é retorno para outro), que também necessita de outro dado para que o quadro analítico fique completo: o valor cobrado pelo serviço. Como foi visto neste artigo, o desequilíbrio do frete-retorno não pode ser demonstrado apenas pela relação caminhão cheio $\mathrm{x}$ caminhão vazio, mas principalmente pelos valores cobrados na ida e na volta.

As pesquisas de origem-destino poderiam inserir esta variável nos questionários, além de outra desprezada, mas de fundamental importância para decifrar o uso do território: qual agente está transportando a carga no trecho abordado? O autônomo, a empresa transportadora contratada pelo embarcador ou a empresa transportadora subcontratada por outra empresa transportadora? A partir desta constatação, teríamos melhores condições de verificar o funcionamento estrutural da cadeia de subcontratações, relacionando-a com o tipo de carga, veículo e rota praticada, mas desconfiamos que não é do interesse do circuito superior do TRC torná-lo mais transparente. 


\section{O Bibliografia}

"Castillo, R. A. (2011). Agricultura globalizada e logística nos cerrados brasileiros. In: Silveira, M. R. (org.) Circulação, transportes e logística. São Paulo, Outras Expressões, pp.331-54.

» CNT (Confederação Nacional do Transporte), SEST (Serviço Social do Transporte) e SENAT (Serviço Nacional de Aprendizagem do Transporte) (2013) Relatório síntese de informações ambientais: caminhoneiros no Brasil autônomos e empregados de frota. Disponível em: <http://www.cntdespoluir. org.br/Documents/pdfs/Relatorio_Sintese_de_Informacoes_Ambientais.pdf>. Acesso em: 21 maio 2013.

"Estado de São Paulo (2006) Pesquisa de origem e destino do transporte rodoviário e aéreo do Estado de São Paulo. São Paulo, Secretaria dos Transportes.

» Huertas, D. M. (2013) Território e circulação: transporte rodoviário de carga no Brasil, Tese de Doutorado, Departamento de Geografia, Universidade de São Paulo (USP).

"Santos, M. (2008) O espaço dividido: os dois circuitos da economia urbana dos países subdesenvolvidos. São Paulo: Edusp.

» Silveira, M. R. (2009) Sistemas de movimento, fluxos econômicos e interações espaciais no território paulista: uma abordagem para a geografia dos transportes e circulação. Scripta Nova, XIII - 1-22.

\section{Daniel Monteiro Huertas / dmhuertas@unifesp.br}

Autor dos livros Território e circulação: transporte rodoviário de carga no Brasil (Unifesp, 2018) e Da fachada atlântica à imensidão amazônica: fronteira agrícola e integração territorial (Annablume, 2009), exerce o cargo de professor adjunto do Departamento Multidisciplinar (Eixo Comum) da Universidade Federal de São Paulo (Unifesp), campus Osasco. É doutor e mestre em Geografia Humana pela Universidade de São Paulo (USP), com graduação em geografia pela Universidade Federal de Uberlândia (UFU). 